\title{
Kinetic Modeling using the Single-Event Methodology: Application to the Isomerization of Light Paraffins
}

\author{
K. Surla, D. Guillaume, J.J. Verstraete and P. Galtier \\ IFP Energies nouvelles, Rond-point de l'échangeur de Solaize, BP 3, 69360 Solaize - France \\ e-mail: karine.surla@ifpen.fr - denis.guillaume@ifpen.fr - jan.verstraete@ifpen.fr - pierre.galtier@ifpen.fr
}

\begin{abstract}
Résumé - Modélisation cinétique basée sur la méthodologie des événements constitutifs : application à l'isomérisation des paraffines légères - L'établissement de modèles cinétiques est une étape importante du développement de procédés de raffinage. En effet, ces modèles peuvent être utilisés pour prédire les performances du procédé, pour optimiser l'opération de l'unité et pour concevoir de façon optimale le réacteur et le procédé associé (choix du réacteur, détermination des conditions de marche optimale, utilisation de recyclages, etc.). La demande actuelle de modèles se focalise particulièrement sur la mise au point de modèles détaillés et prédictifs, qui sont capables de prendre en compte des variations importantes dans la conduite du procédé. De ce fait, ils doivent être extrapolables à des conditions opératoires très différentes ou à des charges très diverses.

La modélisation cinétique par événements constitutifs satisfait ces critères car elle permet d'obtenir une prédiction détaillée des effluents des réacteurs. La théorie des événements constitutifs a été initialement développée pour la chimie radicalaire [Clymans et Froment (1984) Comput. Chem. Eng. 8, 2, 137-142; Hillewaert et al. (1988) AIChE J. 34, 1, 17-24; Willems et Froment (1988a) Ind. Eng. Chem. Res. 27, 11, 1959-1966; Willems et Froment (1988b) Ind. Eng. Chem. Res. 27, 11, 1966-1971] et a été étendue ultérieurement à la catalyse acide [Baltanas et Froment (1985) Comput. Chem. Eng. 9, 1, 71-81; Baltanas et al. (1989) Ind. Eng. Chem. Res. 28, 899-910; Vynckier et Froment (1991) Modeling of the kinetics of complex processes upon elementary steps, in Kinetic and thermodynamic lumping of multicomponent mixtures, Astarita G., Sandler S.I. (eds), Elsevier Science Publishers BV, Amsterdam, pp. 131-161], ainsi qu'à la catalyse métallique [Lozano-Blanco et al. (2006) Oil Gas Sci. Technol. 61, 4, 489-496; LozanoBlanco et al. (2008) Ind. Eng. Chem. Res. 47, 16, 5879-5891]. Cette méthodologie développée au "Laboratorium voor Petrochemische Techniek" à l'Université de Gand consiste à construire un réseau réactionnel exhaustif mais décrit par un nombre limité de paramètres cinétiques indépendants. Le comportement de charges complexes peut alors être prédit sur la base d'études effectuées sur des molécules modèles. Cette méthodologie est appliquée par IFP Energies nouvelles à plusieurs procédés de raffinage. L'objet de cet article est de décrire cette méthodologie de façon détaillée et de présenter son application à l'isomérisation des paraffines C5-C6.
\end{abstract}

Abstract - Kinetic Modeling using the Single-Event Methodology: Application to the Isomerization of Light Paraffins - The construction of kinetic models is an important step in the development of refining processes. Indeed, these models can be used to predict the performances of the process, to optimize the operation of a unit and to optimally design a reactor and the associated process (choice of the reactor configuration, determination of optimal operating conditions, use of recycles, etc.). The current demand for models is particularly focused towards the development of detailed predictive models that are able to 


\begin{abstract}
account for significant changes in process operation. Hence, they need to allow for the extrapolation to considerably different operating conditions or to very diverse feedstocks.

Kinetic modeling based on the single-event theory meets these requirements, since it allows detailed prediction of the composition, and hence the yield structure from the reactors. The single-event theory was initially developed for the radical chemistry occurring during thermal cracking [Clymans and Froment (1984) Comput. Chem. Eng. 8, 2, 137-142; Hillewaert et al. (1988) AIChE J. 34, 1, 17-24; Willems and Froment (1988a) Ind. Eng. Chem. Res. 27, 11, 1959-1966; Willems and Froment (1988b) Ind. Eng. Chem. Res. 27, 11, 1966-1971], later extended to acid catalysis [Baltanas and Froment (1985) Comput. Chem. Eng. 9, 1, 71-81; Baltanas et al. (1989) Ind. Eng. Chem. Res. 28, 899-910; Vynckier and Froment (1991) Modeling of the kinetics of complex processes upon elementary steps, in Kinetic and thermodynamic lumping of multicomponent mixtures, Astarita G., Sandler S.I. (eds), Elsevier Science Publishers BV, Amsterdam, pp. 131-161], and recently adapted to metal catalyzed processes [LozanoBlanco et al. (2006) Oil Gas Sci. Technol. 61, 4, 489-496; Lozano-Blanco et al. (2008) Ind. Eng. Chem. Res. 47, 16, 5879-5891]. This methodology developed in the "Laboratorium voor Petrochemische Techniek" at Ghent University consists in constructing a reaction network which, although exhaustive, is described by a limited number of independent kinetic parameters. The behavior of complex feedstocks can therefore be predicted based on studies conducted on model molecules. This method is applied at IFP Energies nouvelles to several refining processes. The purpose of this article is to describe this methodology in a detailed manner and to present its application to the isomerization of C5-C6 paraffins.
\end{abstract}

\section{INTRODUCTION}

Refining processes convert hydrocarbon feedstocks composed of thousands of species into valuable oil fractions (gasoline/kerosene/gas oil or other) according to highly complex reaction mechanisms. Numerous refining processes (e.g. isomerization, reforming, hydrocracking) are based on bifunctional metal/acid catalysts. In these processes, the acid catalyzed transformations, and even their elementary mechanisms, are now fully understood (Marcilly, 2003). As these elementary steps have been determined, it is therefore possible to build the entire reaction network. This is usually performed by means of computers in order to ensure the exhaustive generation of reactions and species from a given feedstock (Clymans and Froment, 1984; Baltanas and Froment, 1985). However, the number of reactions and species remains too high for the reaction network to be simulated without making any additional assumptions. In particular, the number of kinetic parameters required would be far too great to obtain significant parameters from experimental data. The single-event concept links the reactivity of a molecule to its geometry and to a limited number of intrinsic kinetic parameters, which depend only on the type of molecule and the type of reaction. In this case, it becomes possible to build detailed kinetic models while retaining all reaction pathways. The single-event approach has been applied to many acid-catalyzed processes, amongst which are isomerization, alkylation, olefin oligomerisation, methanol-to-olefins, catalytic reforming, catalytic cracking and hydrocracking. The largest body of work on single event kinetics concerns catalytic cracking (Feng et al., 1993; Dewachtere et al., 1999; Beirnaert et al., 2001; Moustafa and Froment, 2003; Froment, 2005; Quintana-Solórzano et al., 2005, 2007a, b, 2010) and hydroc- racking (Baltanas and Froment, 1985; Baltanas et al., 1989; Vynckier and Froment, 1991; Svoboda et al., 1995; Schweitzer et al., 1999; Martens and Froment, 1999; Martens et al., 2000, 2001; Martens and Marin, 2001; Thybaut et al., 2001, 2004, 2009; Thybaut and Marin, 2003; Laxmi Narasimhan et al., 2003a, b, 2004, 2006, 2007; ChavarríaHernández et al., 2004, 2008; Kumar and Froment, 2007a, b; Chavarría-Hernández and Ramírez, 2009; Mitsios et al., 2009; Choudhury et al., 2010). This paper describes the basic concepts of the single-event kinetic modeling methodology and its application to C5-C6 light paraffin isomerization reactions, hereby extending previous work (Guillaume et al., 2003; Surla et al., 2004).

\section{SINGLE-EVENT KINETIC MODELING}

\subsection{Determining the Elementary Steps Involved in the Transformations}

The first step in the single-event methodology consists in determining all the elementary steps involved in the various transformations that occur in the reactor. To this aim, one needs to define the reaction mechanisms of the chemical phenomena taking place.

The chemical reactions taken into account when generating the network obviously depend on the process to be modeled. In the case of the isomerization of $\mathrm{C} 5$ and $\mathrm{C} 6$ paraffins over bifunctional catalysts, it is generally accepted that most of the molecular rearrangements take place on the acid phase of the catalyst. The mechanism proposed by Mills et al. (1953) is therefore usually retained. In this mechanism (Fig. 1), the 


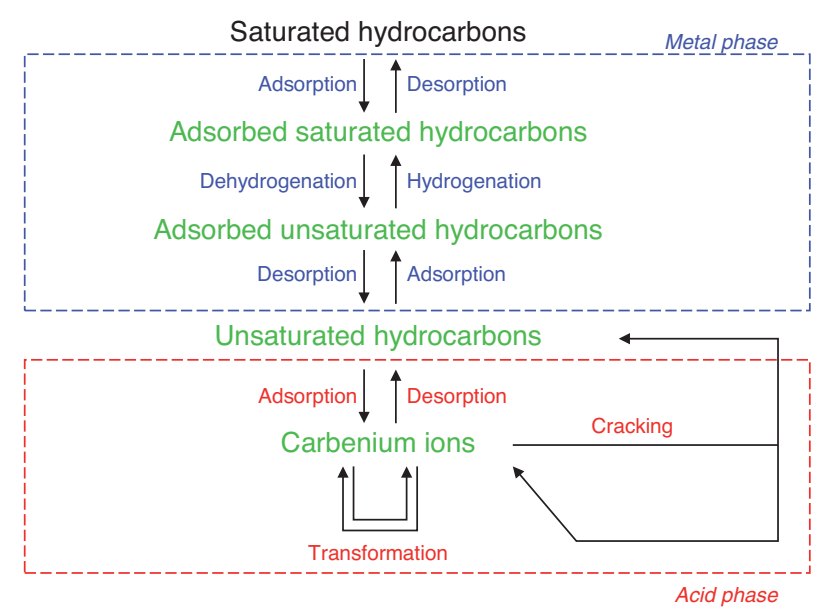

Figure 1

Reaction mechanism proposed by Mills et al. (1953).

saturated compounds, such as paraffins and naphthenes, are first dehydrogenated into olefinic species on the metal sites of the catalyst. Subsequently, the resulting olefins adsorb on the acid sites, where they undergo skeletal isomerization, before desorbing as isomerized olefins. The latter are finally hydrogenated into saturated compounds. In the operating conditions of skeletal isomerization of C5 and C6 paraffins, it is commonly accepted that the reactions on the metal phase reach thermodynamic equilibrium. Hence, the rate determining steps take place on the acid sites of the catalyst. Carbocations are generally considered as reaction intermediates for reactions on acid sites. The carbenium ion chemistry of acid catalyzed reactions has been extensively documented in the literature, and an excellent overview is given by Marcilly (2003). This information will now be used to describe the reaction pathways in detail.

Starting from an olefinic species in the bulk phase, the first step in the reaction mechanism is the formation of the carbenium ion intermediate on the acid phase. This proceeds through the addition of a proton to the olefin. Depending on the structure of the reactant, acyclic or cyclic carbocations are formed. These ions can now undergo isomerization reactions such as hydride, methyl and ethyl shifts, PCP (Protonated CycloPropane) branching or $\beta$-scission. Unsaturated carbenium ions may produce cyclic ions through intramolecular protonation. Deprotonation yields olefins and diolefins corresponding to the various surface ions. All these elementary steps are depicted in Figure 2.

\subsection{Generating the Reaction Network}

Knowing the various types of elementary steps involved in the transformations, it is possible to generate the reaction network. Considering the large number of species and reactions involved in refining processes, it is more convenient to exhaustively generate the reaction network ion by means of a computer algorithm. The algorithm required for this operation has been initially developed at the "Laboratorium voor Petrochemische Techniek" from the Ghent University (Baltanas and Froment, 1985). This algorithm uses a numerical representation of the various types of species involved, which will be described in the paragraph below.

\subsubsection{Numerical Representation of the Molecules}

Computer generation of a reaction network requires the use of a unique numerical encoding of the various molecules and reaction intermediates. In the single-event software, Boolean connectivity matrices are used. In such matrices, elements $m_{i j}$ and $m_{j i}$ of the matrix are equal to 1 if there is a bond between atoms $i$ and $j$. If on the contrary there is no bond between $i$ and $j$, the values of $m_{i j}$ and $m_{j i}$ are 0 . Using these connectivity matrices allows to easily store the structure of the molecule. Boolean connectivity matrices alone are nevertheless insufficient, since the presence of possible double bonds and/or charged atoms does not appear. An auxiliary vector is therefore used to store the information concerning the double bonds, while a scalar tracks which carbon atom carries the charge. As an example, the carbenium ion shown in Figure 3 is coded by the Boolean matrix and the auxiliary vector and scalar in Figure 4.

This matrix representation is a convenient method to numerically store various species. Its advantages reside in the fact that the molecular structure is directly visible, facilitating the generation of reactions and of the corresponding products. However, a molecular species can be described by several matrix representations. Hence, matrix representations are not suited to store species involved in the network, as they do not univocally characterize a molecule. Moreover, their sparseness also impedes efficient memory management.

To tackle the above-mentioned drawbacks, a representation by means of standardized labels is used for the storage of the species involved in the reaction network (Vynckier and Froment, 1991). This label can be broken down into three vectors: the first one is of dimension 1 , and the others are of dimension $N$, where $N$ is the number of carbon atoms in the molecule. The first vector contains the index of the carbon atom carrying the charge of a carbenium ion, and is zero otherwise. The second vector indicates whether the carbon atoms are primary, secondary, tertiary or quaternary. The last one indicates the types of the carbon atoms present in the species considered. By convention, 8 will designate a saturated acyclic carbon atom, 7 an unsaturated acyclic carbon atom, 6 a saturated cyclic carbon atom, 5 an unsaturated cyclic carbon atom, 4 an aromatic carbon atom, 3 a saturated naphthenic bridgehead atom, 2 an unsaturated naphthenic bridgehead atom and 1 an aromatic bridgehead atom. 
Protonation / Deprotonation:

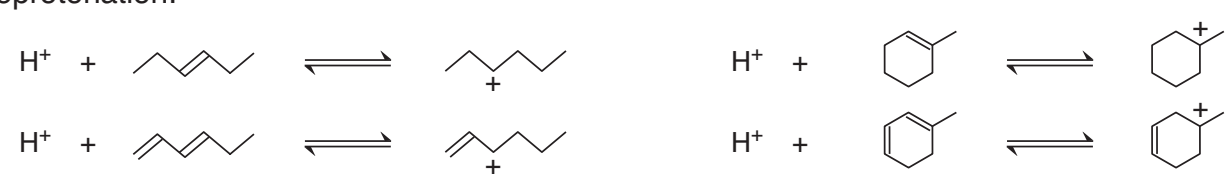

Reactions of acyclic ions:

Saturated acyclic carbenium ions

Hydride shift

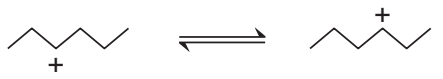

Methyl shift<smiles>C[CH+]C(C)CC</smiles><smiles>C=C</smiles>

Ethyl shift<smiles>C[C+]C(CC)CC</smiles><smiles>CC[C+](C)C(C)C</smiles><smiles>CCC(C)CC</smiles>

Unsaturated acyclic carbenium ions

Cyclisation<smiles>C=CCCC[C+]C</smiles><smiles>C1CC1</smiles><smiles>C[C+]1CCC(C)C1</smiles>

Reactions of cyclic ions:

Saturated cyclic carbenium ions

Hydride shift<smiles>CC1[C+]CCCC1</smiles>

Methyl shift

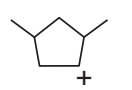

Endocyclic IntraRing Alkyl shift<smiles>CC1[C+]CCCC1</smiles>
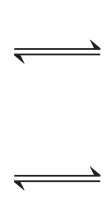<smiles>C[C+]1CCCCC1</smiles><smiles>CC1[CH+]CC(C)C1</smiles>

$\rightleftharpoons$

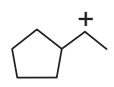

Figure 2

Elementary steps involved on the acid sites during the skeletal isomerization on bifunctional catalysts.

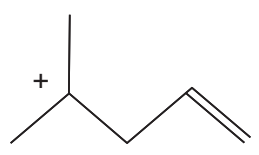

Figure 3

Graphical representation of an unsaturated carbenium ion.

To ensure label encoding is unique, rules are imposed on numbering the carbon atoms. The rules were chosen to reflect the IUPAC naming rules as closely as possible. They are applied in the order of priority in which they are listed below. The carbon atoms of the main structure, the chain for
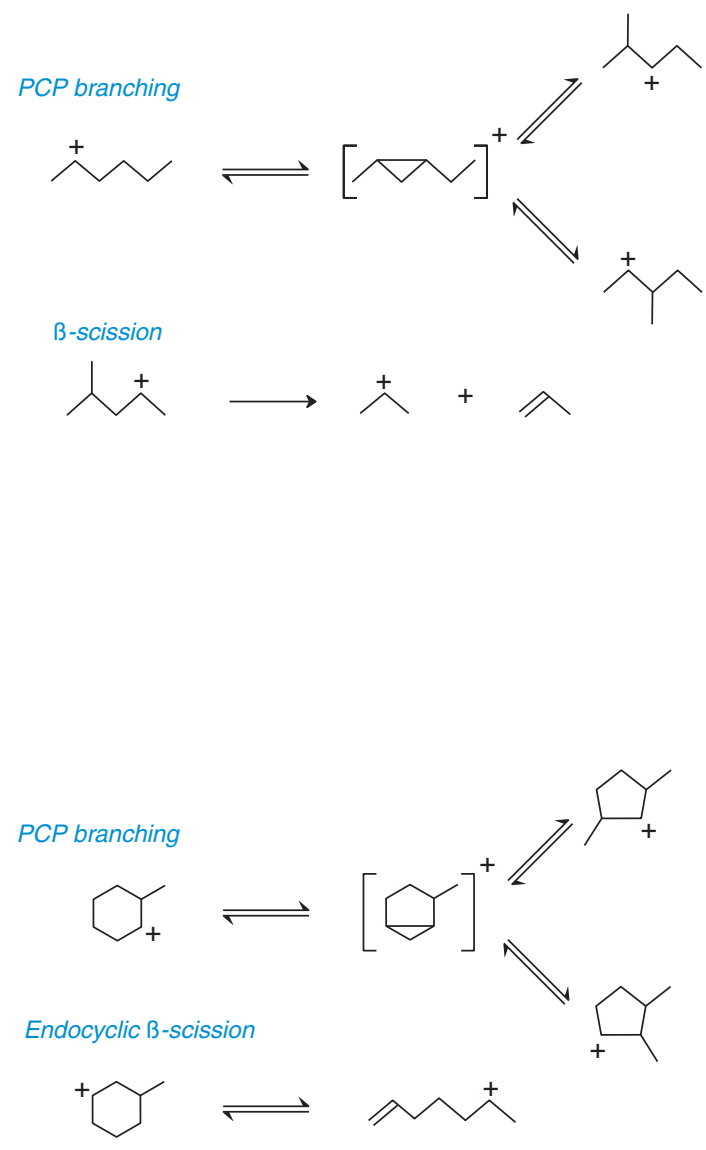

the acyclic compounds, the ring for the cyclic compounds, are numbered first. If the charge is in the main structure, the number of the carbon atom carrying the charge should be as small as possible. The numbers of the unsaturated carbon atoms in the main structure should then be as small as possible. Finally, the numbers of the most substituted carbon atoms in the main structure should be as small as possible. As an example, the label corresponding to the ion shown in Figure 3 is given in Figure 5.

\subsubsection{Numerical Representation of the Reactions}

The elementary steps are carried out by operations on the Boolean connectivity matrices of the reactants (Clymans and 


\begin{tabular}{c|ccccccccc} 
& C1 & C2 & C3 & C4 & C5 & C6 & & & \\
\hline C1 & 0 & 1 & 0 & 0 & 0 & 0 & C1 & 0 & Charge: 2 \\
C2 & 1 & 0 & 1 & 0 & 0 & 1 & C2 & 0 & \\
C3 & 0 & 1 & 0 & 1 & 0 & 0 & C3 & 0 & \\
C4 & 0 & 0 & 1 & 0 & 1 & 0 & C4 & 1 & \\
C5 & 0 & 0 & 0 & 1 & 0 & 0 & C5 & 1 & \\
C6 & 0 & 1 & 0 & 0 & 0 & 0 & C6 & 0 &
\end{tabular}

Figure 4

Matrix representation of the ion.

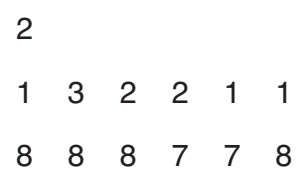

Figure 5

Label representation of the ion in Figure 3.
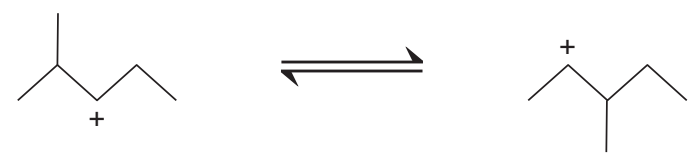

Figure 6

Graphical representation of a methyl shift.

\begin{tabular}{|c|c|c|c|c|c|c|c|c|c|}
\hline & C1 & C2 & C3 & C4 & C5 & C6 & & & \\
\hline C1 & 0 & 1 & 0 & 0 & 0 & 0 & $\mathrm{C} 1$ & 0 & Charge: 3 \\
\hline $\mathrm{C} 2$ & 1 & 0 & 1 & 0 & 0 & 1 & $\mathrm{C} 2$ & 0 & \\
\hline C3 & 0 & 1 & 0 & 1 & 0 & 0 & C3 & 0 & \\
\hline C4 & 0 & 0 & 1 & 0 & 1 & 0 & C4 & 0 & \\
\hline C5 & 0 & 0 & 0 & 1 & 0 & 0 & C5 & 0 & \\
\hline C6 & 0 & 1 & 0 & 0 & 0 & 0 & C6 & 0 & \\
\hline
\end{tabular}

Figure 7

Boolean matrix of the reactant ion.

Froment, 1984; Baltanas and Froment, 1985). By way of example, the methyl shift shown in Figure 6 will be used.

The Boolean matrix of the reactant ion is given in Figure 7.

During the methyl shift, the carbon-carbon bond between carbon atom 2 and carbon atom 6 is broken, and a bond is created between carbon atoms 3 and 6 . At the same time, the charge moves from atom 3 to atom 2. Numerically, the methyl shift is represented by setting matrix elements $m_{26}$

\begin{tabular}{|c|c|c|c|c|c|c|c|c|c|}
\hline & $\mathrm{C} 1$ & $\mathrm{C} 2$ & C3 & $\mathrm{C} 4$ & C5 & C6 & & & \\
\hline C1 & 0 & 1 & 0 & 0 & 0 & 0 & $\mathrm{C} 1$ & 0 & Charge: 2 \\
\hline $\mathrm{C} 2$ & 1 & 0 & 1 & 0 & 0 & 0 & $\mathrm{C} 2$ & 0 & \\
\hline C3 & 0 & 1 & 0 & 1 & 0 & 1 & C3 & 0 & \\
\hline C4 & 0 & 0 & 1 & 0 & 1 & 0 & $\mathrm{C} 4$ & 0 & \\
\hline C5 & 0 & 0 & 0 & 1 & 0 & 0 & C5 & 0 & \\
\hline C6 & 0 & 0 & 1 & 0 & 0 & 0 & C6 & 0 & \\
\hline
\end{tabular}

Figure 8

Matrix of the reaction product.

and $m_{62}$ to zero, and putting matrix elements $m_{36}$ and $m_{63}$ to 1. At the same time, the scalar containing the carbon atom number of the charge is put to 2 . In this way, the matrix of the reaction product is created, as shown in Figure 8.

For the other isomerization reactions through elementary shifts or PCP branching steps, a similar procedure is applied. For the protonation, deprotonation, and cyclisation reactions, the auxiliary vector must also be changed. In the special case of cracking through $\beta$-scission, the resulting Boolean matrix contains the carbon atoms of the two product species $M_{1}$ and $M_{2}$. Hence, the product matrix is composed of four independent blocks of the following form:

$$
\left[\begin{array}{cc}
M_{1} & 0 \\
0 & M_{2}
\end{array}\right]
$$

and needs to be divided into two new matrices, each containing one of the product species.

\subsubsection{Network Generation}

A generic computer algorithm has been developed at the "Laboratorium voor Petrochemische Techniek" from the Ghent University, initially for the radical chemistry occurring during thermal cracking (Clymans and Froment, 1984; Hillewaert et al., 1988; Willems and Froment, 1988a, b), later for acid catalyzed processes (Baltanas and Froment, 1985; Baltanas et al., 1989; Vynckier and Froment, 1991; Svoboda et al., 1995), and recently extended to metal catalyzed processes (Lozano-Blanco et al., 2006, 2008). The algorithm allows generating all reactions, intermediates and products for a given feedstock. To this aim, the user defines the reaction steps that are actually involved, or playing a major role, for the process to be modeled.

A qualitative description of the feedstock components, which are encoded as labels, is first supplied as input data. The computer algorithm reads each feed molecule and applies all chemically possible elementary reactions on this molecule. All resulting reactions and reaction products are numbered and stored. The algorithm then systematically 
repeats the same procedure on all new products until all species have been treated. In this way, the program exhaustively generates the reaction network by creating files classifying the formed products by product family and the generated reactions by reaction type.

\subsection{The Single-Event Principle}

Once the reaction network has been generated, reaction kinetics has to be associated to each reaction: in other words, a rate law with its corresponding kinetic constant must be determined. However, given that a large number of reactions is usually generated, the number of kinetic parameters required would be far too great to obtain significant parameters from experimental data. The single-event concept links the reactivity of a molecule to its geometry and to a limited number of intrinsic kinetic parameters, which depend only on the type of molecule and the type of reaction.

\subsubsection{Stability Considerations Concerning Carbenium Ions}

Rate coefficients are directly related to the activation enthalpy and the activation entropy of the corresponding reaction. As these activation parameters are related to the standard enthalpy and the standard entropy of formation of the activated complex and of the reactant, further information concerning the stability of carbenium ions is first analyzed.

Looking at the values of the standard enthalpy of formation of carbenium ions reported in literature (Tab. l), it can be noticed that, for a given number of carbon atoms, the standard enthalpy of formation mainly depends on the number of carbon-carbon bonds in $\alpha$ position with respect to the charge of the molecule. Indeed, only minor differences are found between carbenium ions of the same type (primary, secondary or tertiary), while significant differences exist (about 70 to $80 \mathrm{~kJ} / \mathrm{mol}$ ) between carbenium ions of a different type, i.e. with a different number of $\alpha$ carbon-carbon bonds. This is even more clearly illustrated when looking at homologous series of carbenium ions, as shown in Table 2 and graphically represented in Figure 9. The important information to retain from these data is that the difference in standard enthalpy of formation between primary and secondary carbenium ions, or between secondary and tertiary carbenium ions, is independent of carbon atom number.

After compiling available literature data and results of quantum chemical calculations on carbenium ions, Martinis (2004) determined the group contribution values for seven additional carbenium ion groups for the Benson's group contribution method (Benson et al., 1969; Benson, 1976) for the standard enthalpy of formation. With this additional development, the Benson group contribution method turned out to be remarkably accurate. Again, the most influential element on the standard enthalpy of formation of a gas-phase carbenium ion is the type of the carbenium ion, i.e. the number of $\alpha$ carbon-carbon bonds (Martinis, 2004).
More recent studies investigated the exact nature of the intermediates for solid acid-catalyzed reactions. Indeed, it was proposed that surface alkoxides are in fact the most energy favored species to serve as stable reaction intermediates (Kazansky et al., 1996; Rigby et al., 1997; Kazansky, 1999; Natal-Santiago et al., 1999). In this view, a covalent carbonyl bond is responsible for binding the alkoxide to the catalytic surface. Thus, as the reaction proceeds, the carbonyl bond stretches until a highly polarized carbocation-like structure becomes a transition state towards the reaction products. Hence, the nature of this resulting carbenium ion-like transition state will determine the effective energy barrier for the reaction, and therefore, its relative reactivity. Their similarity with the carbenium ion intermediates during hydrocarbon transformations in solution constitutes the basis for describing the chemistry of surface alkoxides by means of surfacebonded carbenium ions acting as reaction intermediates (Kazansky, 1999). The two approaches become equivalent after the introduction of the concept of stabilization energy, a concept that accounts for the energy differences between gas phase carbenium ions and their corresponding covalently surface-bonded alkoxy intermediates (Martens et al., 2000; Thybaut et al., 2001).

\subsubsection{Breaking Down an Elementary Step into Single Events}

As mentioned before, it is commonly accepted that, in the case of skeletal isomerization of C5 and C6 paraffins, the reactions on the metal phase reach thermodynamic equilibrium. Hence, only the rate coefficients of the steps taking place on the acid sites of the catalyst are required. These are

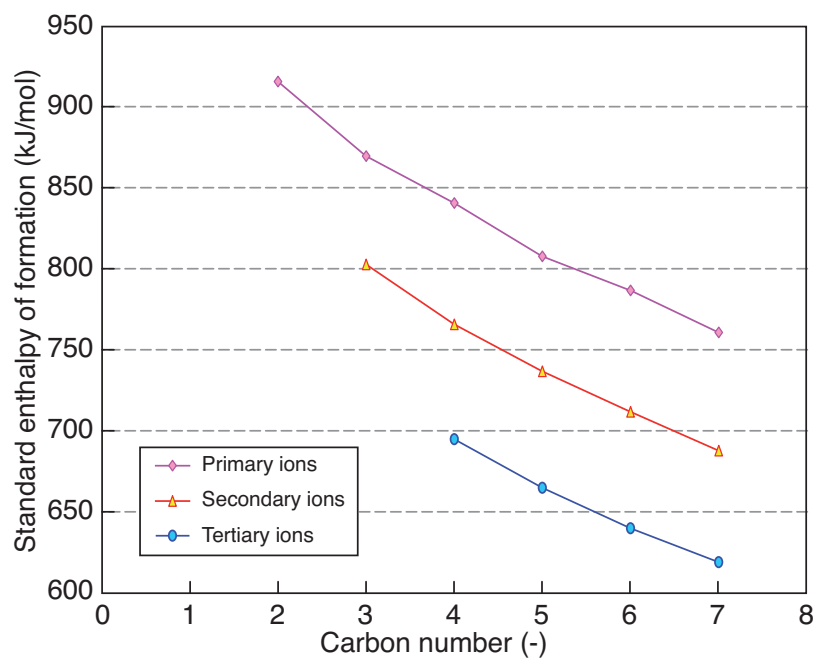

Figure 9

Gas phase enthalpies of formation for the homologous series of carbenium ions of Table 2 (Lenoir and Siehl, 1990). 
TABLE 1

Gas phase enthalpies of formation of some carbenium ions up to $\mathrm{C} 7$

(Lossing and Semeluk, 1970; Pines, 1981; Vogel, 1985; Lenoir and Siehl, 1990; Marcilly, 2003)

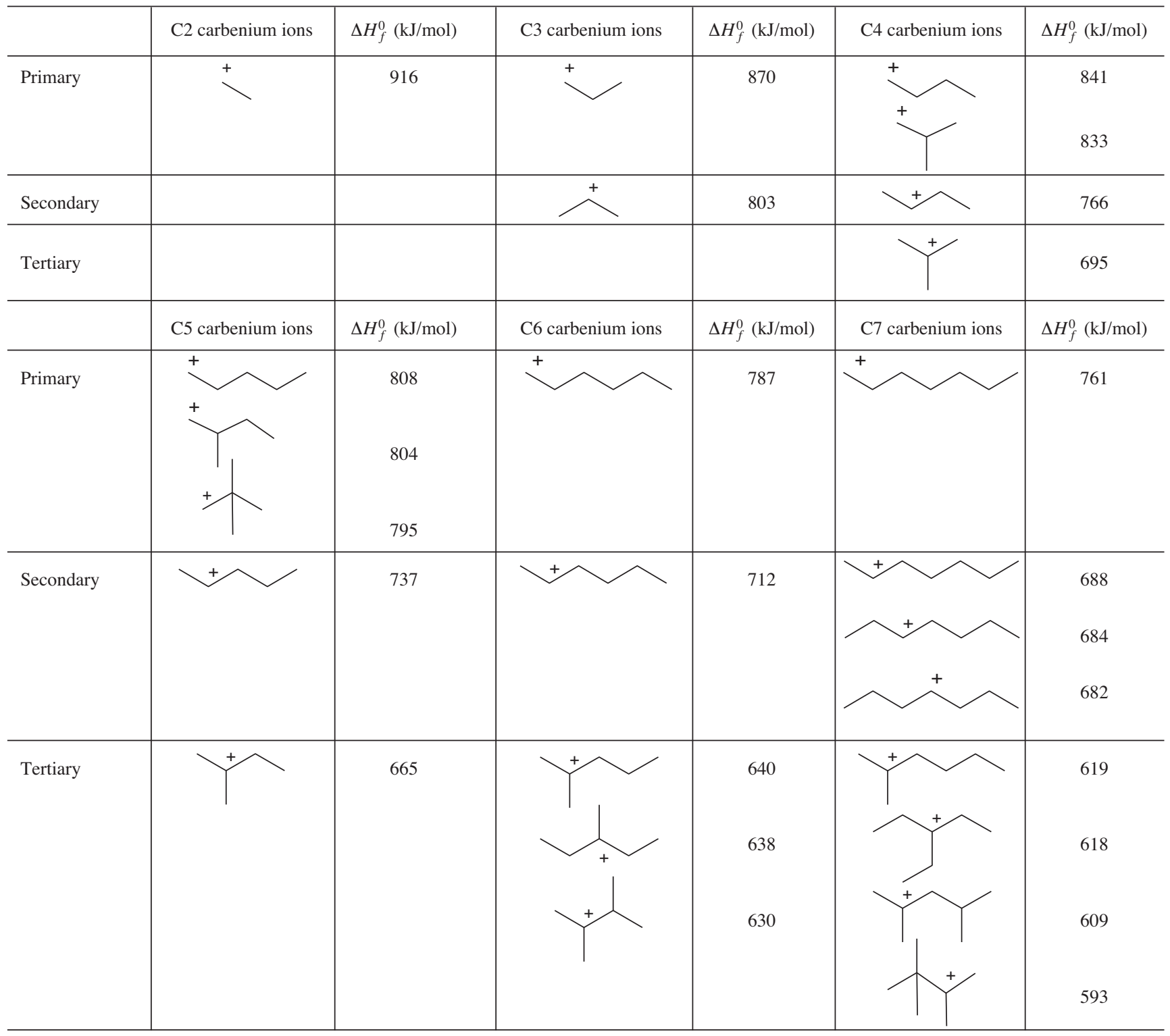

presented in Figure 2 and are elementary steps. The rate of an elementary reaction is assumed to follow the mass action law. For the generated reaction network, the reactions are therefore first order with respect to the concentration of each reactant.

The associated rate constants depend on the structures of the reactants and of the products. For example, for a methyl shift between two secondary carbenium ions (shown in Fig. 10), the rate of forward reaction $r_{1-2}$ of the 2-methyl-(3-) hexyl ion to the 3-methyl-(2-) hexyl ion will be equal to:

$$
r_{1-2}=k_{1-2}\left[R_{1}^{+}\right]
$$

where $k_{1-2}$ is the rate coefficient of the forward reaction, $\left[R_{1}^{+}\right]$ the concentration of the 2-methyl-(3-) hexyl ion adsorbed on the acid phase of the catalyst.

In the above example, the forward rate coefficient $k_{1-2}$ is not equal to the backward rate coefficient $k_{2-1}$, even though both elementary steps are a methyl shift from a secondary reactant to a secondary product, which have the same stability. Indeed, from the 2-methyl-(3-) hexyl ion, two methyl groups may migrate to produce the 3-methyl-(2-) hexyl ion whereas only one shift is possible for the reverse reaction.

To obtain a unique parameter for a given type of reaction (e.g. a secondary-secondary methyl shift), the contribution of 
TABLE 2

Gas phase enthalpies of formation for homologous series of carbenium ions (Lenoir and Siehl, 1990)

\begin{tabular}{|c|c|c|c|c|}
\hline Carbenium ions & $\begin{array}{c}\Delta H_{f}^{0} \\
(\mathrm{~kJ} / \mathrm{mol})\end{array}$ & Carbenium ions & $\begin{array}{c}\Delta H_{f}^{0} \\
(\mathrm{~kJ} / \mathrm{mol})\end{array}$ & $\begin{array}{c}\text { Enthalpy } \\
\text { difference } \\
(\mathrm{kJ} / \mathrm{mol})\end{array}$ \\
\hline & 870 & & 803 & -67 \\
\hline & 841 & & 766 & -75 \\
\hline & 808 & & 737 & -71 \\
\hline & 787 & & 712 & -75 \\
\hline & 761 & & 688 & -73 \\
\hline & 766 & & 695 & -71 \\
\hline & 737 & & 665 & -72 \\
\hline & 712 & & 640 & -72 \\
\hline & 688 & & 619 & -69 \\
\hline
\end{tabular}

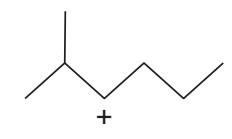

ion $R_{1}^{+}$

2-methyl-(3-) hexyl ion

Figure 10

Shift of a methyl group between two secondary ions.
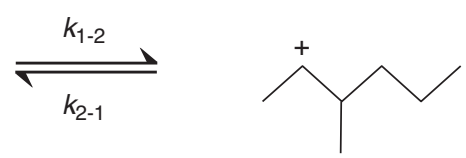

ion $R_{2}^{+}$
3-methyl-(2-) hexyl ion the reaction type needs to be separated from that of the structure of the various species involved. To this aim, the transition state theory will be used. The rate coefficients $k_{1-2}$ and $k_{2-1}$ of the elementary steps shown in Figure 10 can be written according to Eyring's law (Eq. 2):

$$
\begin{aligned}
& k_{1-2}=\frac{k_{B} T}{h} \exp \left(\frac{T \cdot \Delta S_{1-2}^{\mathrm{o \#}}-\Delta H_{1-2}^{\mathrm{o \#}}}{R T}\right) \\
& k_{2-1}=\frac{k_{B} T}{h} \exp \left(\frac{T \cdot \Delta S_{2-1}^{\mathrm{o \#}}-\Delta H_{2-1}^{\mathrm{o \#}}}{R T}\right)
\end{aligned}
$$

where $k_{i-j}$ is the rate coefficient of an elementary step, $k_{B}$ is Boltzmann's constant, $h$ is Planck's constant, $R$ is the ideal gas constant, $T$ is the temperature, $\Delta H^{\circ \#}{ }_{i-j}$ is the activation enthalpy, $\Delta S^{\circ \#}{ }_{i-j}$ is the activation entropy.
The activation enthalpy is the difference between the enthalpy of the activated complex and the enthalpy of the reactant. As a reversible reaction passes over the same activated complex, the difference in activation enthalpy is equal to the difference between the enthalpy of the reactants. As mentioned before (Tab. 1), the standard enthalpy of formation of carbenium ions only depends on the type of ion (secondary or tertiary). Hence, the activation enthalpies for the forward and reverse reactions are very close, and the difference in rate coefficients is mainly due to entropy effects.

The activation entropy for an elementary reaction is the difference between the entropy of the activated complex and the entropy of the reactant. Again, for a reversible reaction passing over the same activated complex, the difference in activation entropy is equal to the difference between the entropy of the reactants.

The standard entropy $S^{\circ}$ of a species can be split into several contributions:

$$
S^{\circ}=S_{\text {trans }}^{\circ}+S_{\text {rot }}^{\circ}+S_{\text {vib }}^{\circ}+S_{\text {elec }}^{\circ}
$$

where $S^{\circ}$ trans is the translational contribution to the standard entropy, $S^{\circ}{ }_{r o t}$ is the rotational contribution to the standard entropy, $S^{\circ}{ }_{v i b}$ is the vibrational contribution to the standard entropy, $S^{\circ}$ elec is the electronic contribution to the standard entropy.

As the reactant and the product of the reaction in Figure 10 are very similar, the translational, vibrational and electronic contributions are the same, but the rotational contributions depend on the symmetry of the molecule (Willems and Froment, 1988a). If the molecule is optically active, the standard entropy must be corrected by adding an asymmetry term related to its chirality. The entropy contributions due to the symmetry of the molecule and to its chirality can be set apart accounting respectively for the number of symmetries $\sigma$ of the compound and the number of diastereo-isomers (Benson, 1976), and the remainder is called the intrinsic standard entropy $S^{\circ}{ }_{\text {int }}$ :

$$
S^{\circ}=S_{\text {int }}^{\circ}-R \ln (\sigma)+R \ln \left(n_{\text {diastereo-isomers }}\right)
$$

where $S^{\circ}{ }_{i n t}$ is the intrinsic standard entropy, $\sigma$ is the symmetry of the molecule (internal and external), $n_{\text {diastereo-isomers }}$ is the number of diastereo-isomers.

Using Equation (4), the activation entropy, which is equal to the entropy difference between the activated complex and the reactant, can be written as:

$$
\begin{aligned}
\Delta S^{\circ \#} & =S^{\circ \#}-S^{\circ r} \\
& =S_{\text {int }}^{\circ \#}-R \ln \left(\sigma^{\#}\right)+R \ln \left(n_{\text {diastereo-isomers }}^{\#}\right) \\
& -\left(S^{\circ r}-R \ln \left(\sigma^{r}\right)+R \ln \left(n_{\text {diastereo-isomers }}^{r}\right)\right) \\
& =\Delta S_{\text {int }}^{\text {o\# }}+R \ln \left(\frac{\sigma_{\text {glob }}^{r}}{\sigma_{\text {glob }}^{\#}}\right)
\end{aligned}
$$


where $\Delta S^{\text {o\# }}$ is the activation entropy, $S^{\text {o\# }}$ is the standard entropy of the activated complex, $S^{\circ r}$ is the standard entropy of the reactant, $S^{\text {o\# }}{ }_{\text {int }}$ is the intrinsic standard entropy of the activated complex, $R$ is the ideal gas constant, $\sigma^{\#}$ is the symmetry of the activated complex, $n_{d i a}^{\#}$ is the number of diastereo-isomers of the activated complex, $S^{\circ r}$ is the intrinsic standard entropy of the reactant, $\sigma^{r}$ is the symmetry of the reactant, $n_{\text {dia }}^{r}$ is the number of diastereo-isomers of the reac$\operatorname{tant}, \Delta S^{o \#}{ }_{\text {int }}$ is the intrinsic activation entropy, $\sigma^{\#}{ }_{g l o b}$ is the global symmetry number of the activated complex, $\sigma_{\text {glob }}^{r}$ is the global symmetry number of the reactant.

The rate constant $k$ can now be written as:

$$
\begin{aligned}
k & =\frac{\sigma_{g l o b}^{r}}{\sigma_{g l o b}^{\#}} \times \frac{k_{B} T}{h} \exp \left(\frac{T \cdot \Delta S_{\text {int }}^{\mathrm{o \#}}-\Delta H^{\mathrm{o \#}}}{R T}\right) \\
& =n_{e} \times \tilde{k}
\end{aligned}
$$

where $k$ is the rate coefficient of the elementary step, $\tilde{k}$ is the intrinsic rate coefficient of the elementary step, also termed the single event rate coefficient, $n_{e}$ represents the number of single events.

In summary, the intrinsic rate coefficient of the elementary step, or single event rate coefficient, depends only on the enthalpy differences between the activated complex and the reactant carbenium ion, and on the intrinsic entropy differences between the activated complex and the reactant carbenium ion. Along the reaction coordinate pathway from the reactant(s) to the transition state, symmetry axes and chiral centers are created and/or destroyed by changing the bond distances and positions of the carbon atoms in $\alpha$ - and/or $\beta$-position of the atom that carries the positive charge or is part of a double bond. These variation are highly structure dependent and are captured in the global symmetry numbers of the reactant and the transition state (Muller et al., 1991), determining the number of single events of the elementary step.

Reverting back to the example in Figure 10, the rate coefficients $k_{1-2}$ and $k_{2-1}$ of the elementary steps in the transformation of the 2-methyl-(3-) hexyl ion into the 3-methyl(2-) hexyl ion can be written as:

$$
\begin{aligned}
& k_{1-2}=\frac{\sigma_{g l o b}^{1}}{\sigma_{g l o b}^{\#}} \times \frac{k_{B} T}{h} \exp \left(\frac{T \cdot \Delta S_{\mathrm{int,1-2}}^{\mathrm{OH}}-\Delta H_{1-2}^{\mathrm{OH}}}{R T}\right) \\
& k_{2-1}=\frac{\sigma_{g l o b}^{2}}{\sigma_{\text {glob }}^{\#}} \times \frac{k_{B} T}{h} \exp \left(\frac{T \cdot \Delta S_{\mathrm{int}, 2-1}^{\mathrm{OH}}-\Delta H_{2-1}^{\mathrm{OH}}}{R T}\right)
\end{aligned}
$$

In these equations, the activation enthalpies of the forward and the backward reaction and the intrinsic activation entropies of these reactions are the same, since they represent the difference between the value of the activated complex and the respective secondary carbenium ion with the same carbon number. As the global symmetry number of the 2-methyl-(3-) hexyl ion $\left(\sigma_{\text {glob }}^{1}=3^{3}\right)$ is twice the global symmetry number of the 3-methyl-(2-) hexyl ion $\left(\sigma_{\text {glob }}^{2}=3^{3} / 2\right)$, the forward rate coefficient $k_{1-2}$ is twice as high as the backward rate coefficient $k_{2-1}$. Indeed, inspecting the reaction in Figure 10 shows that for the forward reaction 2 methyl groups can be candidate to a methyl shift, while for the backward reaction, only one methyl group is available to carry out the desired reaction:

$$
\begin{aligned}
& k_{1-2}=\frac{\sigma_{g l o b}^{1}}{\sigma_{g l o b}^{\#}} \times \tilde{k} \\
& k_{2-1}=\frac{\sigma_{g l o b}^{2}}{\sigma_{g l o b}^{\#}} \times \tilde{k}
\end{aligned}
$$

\subsubsection{Carbon Number Independence of the Single Event Rate Coefficients}

The carbon number dependence of the single event rate coefficient will depend on the effect of carbon number on the enthalpy differences between the activated complex and the reactant carbenium ion, and on the effect of carbon number on the intrinsic entropy differences between the activated complex and the reactant carbenium ion.

For a given number of carbon atoms, the values of the standard enthalpy of formation of carbenium ions reported in literature (Tab. 1) are mainly determined by the type of carbenium ion (secondary or tertiary). Moreover, as illustrated in Figure 9, the difference in standard enthalpy of formation between primary and secondary carbenium ions, or between secondary and tertiary carbenium ions, is independent of carbon atom number. By extending Benson's group contribution method, Martinis (2004) also arrived at the conclusion that the most influential element on the standard enthalpy of formation of a gas-phase carbenium ion is its type. Concerning the intrinsic standard entropy of formation of the carbenium ion intermediates, a similar reasoning can be made.

As both the carbenium ion intermediates and the activated complexes are considered to have an ionic character, the effect of carbon number on the stability of the carbenium ion and on the stability of the activated complex is expected to be the same (Martens et al., 2000; Thybaut et al., 2001). Indeed, one can reasonably assume that, for the activated complexes of a given carbon number and type of elementary reactions, their standard enthalpy of formation will depend equally exclusively on the "ionic" type of the activated complex, i.e. on the types of the reactant and the product carbenium ions, and that the exact configuration of the activated complex will introduce only minor variations.

Looking at a homologous series of reactions between carbenium ions ( $T a b .2)$, the enthalpy difference between the produced and the reacting carbenium ion does almost not depend on the carbon number, which implies that the enthalpy of reaction will be independent of carbon number. For such a 
homologous series of reactions, it can therefore be reasonably assumed that enthalpy difference between the activated complex and the reactant will equally be independent on the carbon number. Indeed, the activated complex has a conformation that is halfway the conformation of the reactant and that of the product. Consequently, it seems reasonable to assume that the intrinsic rate coefficient of the elementary step, or single event rate coefficient, does not depend on the carbon number, but only on the type of the reaction and the type of reactant and product.

In order to validate this assumed carbon number independence of the single event rate coefficients, Martens et al. (2000) determined the kinetic parameters for the various elementary steps of a single event kinetic model from experimental data for hydrocracking of $n$-octane, $n$-decane, $n$-dodecane, and a mixture of $n$-octane and $n$-decane over a commercial hydrocracking catalyst. In order to further reduce the number of kinetic parameters to be estimated by regression, the pre-exponential factors of the various reactions were calculated from first principles, leaving only 7 composite activation energies to be identified. With these fixed and carbon number independent pre-exponential factors, the values of activation energies were estimated for the 4 experimental data sets separately, and the product distribution and yields were accurately described under varying process conditions. No statistically significant difference was found for most activation energies (Martens et al., 2000), providing an indirect validation of the assumed carbon number independence of the pre-exponential factors and the activation energies.

In conclusion, introducing the single event concept makes it possible to define intrinsic kinetic parameters that depend on the type of elementary step, but are independent of the structure of the reactant ion and transition state, and independent of their carbon number. In this way, the number of rate coefficients of the elementary steps can be reduced to a much smaller number of single event rate coefficients, while the number of single events can be calculated from the global symmetry numbers of the reactant(s) and of the activated complex.

\subsubsection{Calculating the Number of Single Events}

The application of the single event concept requires the knowledge of the number of single events for each elementary step. The number of single events for a given elementary step is by definition of the ratio of the global symmetry number of reactant(s) over that of the transition state.

As presented above, the global symmetry number of a species can be decomposed into the external symmetry number, the internal symmetry number and the number of diastereo-isomers. The calculation of the external symmetry is based on the identification of the center of molecular symmetry. Once identified, simple rules can be applied to determine the external symmetry number $\sigma_{\text {ext }}$. Subsequently, within the molecule, the 2-fold and 3-fold internal symmetry axes, depending on the hybridization state $\left(\mathrm{sp}^{2}\right.$ or $\left.\mathrm{sp}^{3}\right)$ of each atom, are identified to determine the contributions to the internal symmetry number $\sigma_{\text {int }}$. Finally, the chiral centers within the molecule are located to determine the number of diastereo-isomers of the species. To obtain the various symmetry numbers, specific evaluation methods and algorithms for symmetry calculations exist (Benson et al., 1969; Benson, 1976; Baltanas et al., 1989; Vynckier and Froment, 1991; Muller et al., 1991; Walters and Yalkowsky, 1996; Ratkiewicz and Truong, 2003; Martinis and Froment, 2006). With this information, the global symmetry number of a species can then be calculated.

One of the practical difficulties in the calculation of the number of single events arises from the fact that the structure of the transition state is generally unknown. Even though the structure of the transition state could be identified by means of computational chemistry calculations, this technique becomes too costly in terms of the computational effort when dealing with a large number of elementary steps. In order to overcome the difficulties of calculating a very large number of transition state structures, the idea is to come up with an educated guess of the basic features of the transition state for a given type of elementary step, focusing on the stretching of the bonds. By identifying the creation and/or destruction of symmetry axes and chiral centers between the reactant and the transition state, the detailed knowledge of the transition state structure is no longer necessary. Given the basic geometry of the transition state structure for a given reaction type, formulae for the direct estimation of the number of single events can be developed for elementary steps such as hydride shift, methyl shift, PCP branching, $\beta$-scission, oligomerization and hydride transfer, as was done by Vynckier and Froment (1991) and by Martinis and Froment (2006). Similar assumptions have been made in our single event kinetic model and are described in the next section.

The validity of representing free carbenium ion structures to represent surface-bonded structures may also be questionable. However, Park and Froment (2001) studied the effect of the surface bonding of carbenium ions and concluded that both the reactant and the transition state undergo similar reductions in their global symmetry numbers with bonding. Therefore, the number of single events remains the same for reactions of surface-bonded ions as for reaction of free carbenium ions.

\subsubsection{Further Reduction of the Number of Parameters}

As described above, the single event rate coefficient will depend on the type of the reacting carbenium ion and on the type of the activated complex. As the latter species has a conformation that is halfway the conformation of the reactant and that of the product, a number of additional assumptions based on the stability of the carbocations and on the structure of the 
transition state has been introduced to further reduce the number of kinetic parameters required to describe the network.

The kinetic rate coefficients for olefin and diolefin protonation are assumed to depend exclusively on the type of ion formed (secondary and tertiary). This is justified by the similarity of the transition state with the reactive species (Baltanas et al., 1989). This leads to:

$$
\tilde{k}_{p r}\left(O_{i}, R_{m}^{+}\right)=\tilde{k}_{p r}\left(\operatorname{type}\left(R_{m}^{+}\right)\right)=\tilde{k}_{p r}(m)
$$

with the following simplifying notation: $m=$ type $\left(R_{m}^{+}\right)$.

The kinetic constants of deprotonation depend on the reacting ion and the olefin or diolefin produced:

$$
\tilde{k}_{\text {dep }}\left(R_{m}^{+}, O_{i}\right)=\tilde{k}_{\text {dep }}\left(\text { type }\left(R_{m}^{+}\right), O_{i}\right)=\tilde{k}_{\text {dep }}\left(m, O_{i}\right)
$$

The kinetic parameters of isomerization reactions (hydride, methyl, ethyl, endocyclic alkyl shifts, PCP branching) are assumed to depend only on the types of reactant and product ions in the case of saturated carbenium ions. It is also assumed that the ring expansion and ring contraction rate coefficients are equal since the difference in ring tension enthalpy between 5 and 6 atoms is low compared to the difference in enthalpy between secondary and tertiary carbocations. Hence, for each of these reaction types, we have:

$$
\tilde{k}_{\text {isom }}\left(R_{m}^{+}, R_{n}^{+}\right)=\tilde{k}_{\text {isom }}\left(\text { type }\left(R_{m}^{+}\right) \text {,type }\left(R_{n}^{+}\right)\right)=\tilde{k}_{\text {isom }}(m, n)
$$

The acyclic or exocyclic $\boldsymbol{\beta}$-scission steps consist in breaking a carbon-carbon bond in $\beta$ position of the charge. In analogy with deprotonation, which produces an olefin and a proton by breaking a carbon-hydrogen bond in $\beta$ position of the charge, the acyclic or exocyclic $\beta$-scission rate coefficients depend on the type of reactant and product ions and on the olefin formed:

$$
\begin{aligned}
& \quad \tilde{k}_{c r}\left(R_{m}^{+}, R_{n}^{+}, O_{i}\right)=\tilde{k}_{c r}\left(\text { type }\left(R_{m}^{+}\right), \text {type }\left(R_{n}^{+}\right), O_{i}\right) \\
& =\tilde{k}_{c r}\left(m, n, O_{i}\right) \\
& \tilde{k}_{\text {exo }}\left(N R_{m}^{+}, N R_{n}^{+}, O_{i}\right)=\tilde{k}_{\text {exo }}\left(\text { type }\left(N R_{m}^{+}\right), \text {type }\left(N R_{n}^{+}\right), O_{i}\right) \\
& =\tilde{k}_{\text {exo }}\left(m, n, O_{i}\right) \\
& \tilde{k}_{\text {exo }}\left(N R_{m}^{+}, R_{n}^{+}, N O_{i}\right)=\tilde{k}_{\text {exo }}\left(\text { type }\left(N R_{m}^{+}\right), \text {type }\left(R_{n}^{+}\right), N O_{i}\right) \\
& =\tilde{k}_{\text {exo }}\left(m, n, N O_{i}\right)
\end{aligned}
$$

By analogy to the deprotonation reactions, the rate coefficients of the alkylation steps, i.e. the reverse reaction of the acyclic or exocyclic $\beta$-scission steps are supposed to be independent of the reacting olefin, but only on the type of the reacting and produced carbenium ions.

The endocyclic $\beta$-scission steps produce only a nonconjugated olefinic ion. Consequently, the associated rate coefficients depend only on the type of reactant and product ions:

$$
\begin{aligned}
& \tilde{k}_{\text {endo }}\left(N R_{m}^{+}, O R_{n}^{+}\right)=\tilde{k}_{\text {endo }}\left(\text { type }\left(N R_{m}^{+}\right) \text {,type }\left(O R_{n}^{+}\right)\right) \\
& =\tilde{k}_{\text {endo }}(m, n)
\end{aligned}
$$

Analogously to the protonation reactions, the kinetic parameters of cyclisation reactions, which are the inverse of endocyclic $\beta$-scissions, depend only on the type of reactant and product ions:

$$
\begin{aligned}
& \tilde{k}_{c y c}\left(O R_{m}^{+}, N R_{n}^{+}\right)=\tilde{k}_{c y c}\left(\text { type }\left(O R_{m}^{+}\right), \text {type }\left(N R_{n}^{+}\right)\right) \\
& =\tilde{k}_{c y c}(m, n)
\end{aligned}
$$

We will therefore assume that the single-event constants depend only on the types of the ions involved in the reaction, except in the case of acyclic and endocyclic $\beta$-scissions and of deprotonation, where the rate coefficient also depends on the olefin involved. For example, the shift of a methyl group will be characterized by 4 intrinsic rate coefficients:

- $\widetilde{k}_{\mathrm{MS}}(s, s)$ for a reaction between two secondary ions;

- $\tilde{k}_{\text {MS }}(s, t)$ for a reaction between a secondary ion and a tertiary ion;

- $\tilde{k}_{\mathrm{MS}}(t, t)$ for a reaction between two tertiary ions;

- $\tilde{k}_{\mathrm{MS}}(t, s)$ for a reaction between a tertiary ion and a secondary ion.

Applying this principle to the rate coefficients of the reaction shown in Figure 10, Equation (8) can be rewritten as:

$$
\begin{aligned}
& k_{1-2}=n_{e_{1-2}} \times \tilde{k}_{M S}(s, s) \\
& k_{2-1}=n_{e_{2-1}} \times \tilde{k}_{M S}(s, s)
\end{aligned}
$$

As mentioned above, the number of single events is calculated from the symmetry numbers of the reactant(s) and of the activated complex.

\subsubsection{Thermodynamic Restrictions and Constraints}

As mentioned above, only 4 rate coefficients exist for each type of isomerization reaction between carbenium ions. However, thermodynamic relations can be derived between them, allowing to limit the number of independent rate coefficients to 3 .

For the deprotonation steps and for the acyclic and endocyclic $\beta$-scission, the number of rate coefficients remains relatively high, as the rate coefficients depends also on the produced olefin. However, not all of them are independent as thermodynamic constraints exist, which further reduce the number of rate coefficients.

\section{Protonation/Deprotonation}

The intrinsic constants of the deprotonation steps depend on the type of ion and on the olefin involved. The intrinsic kinetic constant for deprotonation of an ion of type $m$ into an 
olefin $O_{j}, \widetilde{k}_{d e}\left(m ; \mathrm{O}_{j}\right)$, can be written as the product of an intrinsic constant for deprotonation of a reference olefin $O_{\text {ref }}$ and the equilibrium constant between the two olefins considered (Baltanas et al., 1989):

$$
\tilde{k}_{d e}\left(m ; O_{j}\right)=\tilde{k}_{d e}\left(m ; O_{r e f}\right) \cdot \tilde{K}\left(O_{r e f} \Leftrightarrow O_{j}\right)
$$

where $\tilde{K}\left(\mathrm{O}_{r e f} \Leftrightarrow \mathrm{O}_{j}\right)$ represents the intrinsic equilibrium constant, i.e. without contribution of the symmetries.

We can therefore link all the deprotonation constants for type $m$ ions for a given carbon number to a reference rate coefficient $k_{d e}\left(m, O_{r e f}\right)$.

To restrict the number of reference rate coefficient $k_{d e}(m$, $O_{\text {ref }}$ ), one can use a homologous series of reference olefins. For acyclic species, the following reference series is selected: methyl 2-but-2-ene, methyl 2-pent-2-ene, methyl 2-hex-2ene, methyl 2-hept-2-ene. We will further assume that for the series of reference olefins, the deprotonation constant is independent of the number of carbon atoms and therefore:

$$
\begin{aligned}
& \tilde{k}_{d e}\left(m, O_{r e f}\left(n_{c}\right)\right)=\tilde{k}_{d e}\left(m, O_{r e f}\left(n_{c}+1\right)\right)= \\
& \ldots .=\tilde{k}_{d e}\left(m ; O_{r e f}\right)
\end{aligned}
$$

Consequently, deprotonation of olefins can be described with just two adjustable parameters: $\widetilde{k}_{d e}\left(s, O_{r e f}\right)$ and $\widetilde{k}_{d e}\left(t, O_{r e f}\right)$.

Similarly, we have the following relations between the other unsaturated species:

$$
\begin{gathered}
\tilde{k}_{d e}\left(m ; D O_{j}\right)=\tilde{k}_{d e}\left(m ; D O_{r e f}\right) \cdot \tilde{K}\left(D O_{r e f} \Leftrightarrow D O_{j}\right) \\
\tilde{k}_{d e}\left(m ; N O_{j}\right)=\tilde{k}_{d e}\left(m ; N O_{r e f}\right) \cdot \tilde{K}\left(N O_{r e f} \Leftrightarrow N O_{j}\right) \\
\tilde{k}_{d e}\left(m ; N D O_{j}\right)=\tilde{k}_{d e}\left(m ; N D O_{r e f}\right) \cdot \tilde{K}\left(N D O_{r e f} \Leftrightarrow N D O_{j}\right)
\end{gathered}
$$

\section{Isomerization}

The rate coefficients for isomerization depend only on the type of reactant ion and on the type of product ion. Considering the isomerization of olefins $O_{1}$ and $O_{2}$ by the following series of elementary steps:

$$
O_{1}+\mathrm{H}^{+} \Leftrightarrow R_{1}^{+} \Leftrightarrow R_{2}^{+} \Leftrightarrow O_{2}+\mathrm{H}^{+}
$$

a relation can be derived between the isomerization constants of olefins $O_{1}$ and $O_{2}$, ions $R_{1}$ and $R_{2}$, and the equilibrium constants for protonation of olefins $O_{1}$ and $O_{2}$ :

$$
K\left(O_{1} \Leftrightarrow O_{2}\right)=K\left(O_{1} \Leftrightarrow R_{1}^{+}\right) \cdot K\left(R_{1}^{+} \Leftrightarrow R_{2}^{+}\right) \cdot K\left(R_{2}^{+} \Leftrightarrow O_{2}\right)
$$

with the following expressions of the equilibrium constants:

$$
\begin{aligned}
& K\left(R_{1}^{+} \Leftrightarrow R_{2}^{+}\right)=\frac{k_{\text {isom }}\left(m_{1}, m_{2}\right)}{k_{\text {isom }}\left(m_{2}, m_{1}\right)} \\
& K\left(O_{1} \Leftrightarrow R_{1}^{+}\right)=\frac{k_{p r}\left(m_{1}\right)}{k_{d e}\left(m_{1}, O_{1}\right)} \\
& K\left(R_{2}^{+} \Leftrightarrow O_{2}\right)=\frac{k_{d e}\left(m_{2}, O_{2}\right)}{k_{p r}\left(m_{2}\right)}
\end{aligned}
$$

Combining these equations, we obtain the following relation (26):

$$
\begin{aligned}
& k_{\text {isom }}\left(m_{1}, m_{2}\right)= \\
& k_{\text {isom }}\left(m_{2}, m_{1}\right) \cdot \frac{k_{p r}\left(m_{2}\right)}{k_{d e}\left(m_{2}, O_{r e f}\right)} \cdot \frac{k_{d e}\left(m_{1}, O_{r e f}\right)}{k_{p r}\left(m_{1}\right)}
\end{aligned}
$$

Obviously, this relation remains valid when using the fundamental single event rate coefficients:

$$
\begin{aligned}
& \tilde{k}_{\text {isom }}\left(m_{1}, m_{2}\right)= \\
& \tilde{k}_{i s o m}\left(m_{2}, m_{1}\right) \cdot \frac{\tilde{k}_{p r}\left(m_{2}\right)}{\tilde{k}_{d e}\left(m_{2}, O_{r e f}\right)} \cdot \frac{\tilde{k}_{d e}\left(m_{1}, O_{r e f}\right)}{\tilde{k}_{p r}\left(m_{1}\right)}
\end{aligned}
$$

Hence, $k_{i s o}(s, t)$ can be calculated from $k_{i s o}(t, s)$, which reduces the number of independent kinetic parameters to be identified per isomerization type to $3: k_{i s o}(s, t), k_{i s o}(s, s), k_{i s o}(t, t)$. Similarly, extending these relations to the cyclic compounds:

$$
\begin{aligned}
& \tilde{k}_{\text {isom }}\left(m_{1}, m_{2}\right)= \\
& \tilde{k}_{\text {isom }}\left(m_{2}, m_{1}\right) \cdot \frac{\tilde{k}_{p r}\left(m_{2}\right)}{\tilde{k}_{d e}\left(m_{2}, N O_{r e f}\right)} \cdot \frac{\tilde{k}_{d e}\left(m_{1}, N O_{r e f}\right)}{\tilde{k}_{p r}\left(m_{1}\right)}
\end{aligned}
$$

\section{Cracking Reactions}

The $\beta$-scission acyclic cracking reactions are related to the alkylation rate coefficients via the following reaction diagram:

$$
R_{m_{1}}{ }^{+} \stackrel{k_{c r}\left(m_{1} ; m_{2}, O\right)}{\longleftarrow} \underset{k_{a l k}\left(m_{2} ; m_{1}\right)}{\longleftarrow} \quad R_{m_{2}}{ }^{+}+O
$$

Assuming that the alkylation rate coefficients do not depend on the intermediate olefin, the alkylation and protonation rate coefficients are then related by the following Equation (30):

$$
\begin{aligned}
& \frac{k_{c r}\left(m_{1} ; m_{2}, O\right)}{k_{a l k}\left(m_{2} ; m_{1}\right)}=\frac{k_{p r}\left(m_{2}\right)}{k_{d e}\left(m_{2} ; O_{r e f_{m_{2}}}\right)} \cdot \\
& \frac{k_{d e}\left(m_{1} ; O_{r e f_{m_{1}}}\right)}{k_{p r}\left(m_{1}\right)} \cdot K\left(O_{r e f_{m_{1}}} \Leftrightarrow O_{r e f_{m_{2}}}+O\right)
\end{aligned}
$$


This equation remains valid for the fundamental rate coefficients:

$$
\begin{aligned}
& \frac{\tilde{k}_{c r}\left(m_{1} ; m_{2}, O\right)}{\tilde{k}_{a l k}\left(m_{2} ; m_{1}\right)}=\frac{\tilde{k}_{p r}\left(m_{2}\right)}{\tilde{k}_{d e}\left(m_{2} ; O_{r e m_{m_{2}}}\right)} \cdot \frac{\tilde{k}_{d e}\left(m_{1} ; O_{r e f_{m_{1}}}\right)}{\tilde{k}_{p r}\left(m_{1}\right)} . \\
& \tilde{K}\left(O_{r e f_{m_{1}}} \Leftrightarrow O_{r e f_{m_{2}}}+O\right)
\end{aligned}
$$

Hence, one obtains the same thermodynamic constraint as for the deprotonation steps:

$$
\tilde{k}_{c r}\left(m_{1} ; m_{2}, O_{j}\right)=\tilde{k}_{c r}\left(m_{1} ; m_{2}, O_{r e f}\right) \times \tilde{K}\left(O_{r e f} \Leftrightarrow O_{j}\right)
$$

The total number of independent rate coefficients for the $\beta$-scission steps amounts to 4 .

\section{Ring Opening Reactions}

Ring opening reactions proceed through endocyclic cracking reactions. They are related to the cyclisation reactions by the following reaction:

$$
N R_{m}{ }^{+} \stackrel{k_{\text {endo }}(m ; n)}{\underset{k_{c y c}(n ; m)}{\longleftarrow}} \mathrm{OR}_{n}^{+}
$$

The ring opening and cyclisation reactions are therefore related by relation (34):

$$
\begin{aligned}
& k_{\text {endo }}(m ; n)=k_{c y c}(n ; m) \cdot \frac{k_{p r}(n)}{k_{d e}\left(n ; D O_{r e f}\right)} . \\
& \frac{k_{d e}\left(m ; N O_{r e f}\right)}{k_{p r}(m)} \cdot K\left(N O_{r e f} \Leftrightarrow D O_{r e f}\right)
\end{aligned}
$$

The total number of independent rate coefficients for the ring opening steps therefore amounts to 4 , while the rate coefficients for the cyclisation steps can be derived from the above thermodynamic constraint.

\subsubsection{Effect of Catalyst Characteristics on the Single Event Rate Coefficients}

Due to its fundamental character, the single event kinetic model also allows to account for the catalyst characteristics in an elegant manner. Of course, as most models, the model directly contains the total concentration of Brønsted acid sites, which can be measured via ammonia TPD or determined from the framework aluminum content in the case of zeolites. Besides this standard catalyst parameter, Martens $e t$ al. (2000) also introduced a means to account for the difference in acid strength of various Pt/US-Y zeolite catalysts by introducing the heat of stabilization of a carbenium ion relative to the heat of stabilization of a proton as an independent parameter in the composite activation energy. Hence, only this relative stabilization parameter needed to be adjusted to transpose the model from one catalyst to another. Thybaut et al. $(2001,2004)$ further developed this concept. Using as a working hypothesis that the relative stability of the carbenium intermediate and its activated complex is independent of the acid strength, i.e. that the activation energies are independent of the acid strength, these authors attributed this heat of stabilization of a carbenium ion relative to the heat of stabilization of a proton to the difference in the standard protonation enthalpy of the alkenes for different catalysts. More recently, Choudhury et al. (2010) used to same approach to model the hydrocracking of $n$-decane on a non-shape selective $\mathrm{Pt} / \mathrm{NaHY}$ catalyst and a shape selective Pt/H-ZSM-22 catalyst, as well as on physical mixtures of both catalysts.

\section{APPLICATION OF THE SINGLE-EVENT METHODOLOGY TO THE ISOMERIZATION OF C5-C6 LIGHT PARAFFINS}

Isomerization is the best light naphtha octane boosting process for meeting gasoline specifications. Indeed, C5/C6 isomerization leads to products that are sulfur-free, aromatics-free, olefins-free and have a Research Octane Number (RON) of up to 92. Skeletal isomerization of normal into isoparaffins is a reversible and slightly exothermic reaction. Hence, the lower the temperature, the higher the thermodynamic equilibrium ratio of branched isomers over normal paraffin for a given number of carbon atoms.

Two types of catalysts are used for this process:

- Chlorinated alumina - Pt catalysts, which have a high catalytic activity. Consequently, the isomerization process can be carried out at low temperature $\left(130-170^{\circ} \mathrm{C}\right)$ leading to an excellent RON. These catalysts can also be used in once-through mode, i.e. without paraffins recycle. A RON of 82-84 can then be reached with a high equilibrium conversion of normal paraffins to branched isomers; although they are extremely sensitive to impurities, such as oxygenates or water, chlorinated alumina based catalysts are the preferred choice to maximize octane number.

- Zeolite - Pt type catalysts, which are less active than chlorinated alumina catalysts. These catalysts are therefore used at a higher operating temperature $\left(220-260^{\circ} \mathrm{C}\right)$, resulting in slightly reduced octane boost. Zeolite based catalysts are relatively insensitive to oxygen-containing impurities, and no feed pre-treatment is therefore required. Sulfur is a poison for the metallic phase of isomerization catalysts, but its effect is lower than for chlorinated alumina catalysts because of the higher temperature of reaction.

\subsection{Experimental Results}

In order to collect data, tests were carried out in an isothermal plug flow reactor. The reactor was loaded with $200 \mathrm{~cm}^{3}$ of a commercial platinum on chlorinated alumina catalyst. As the catalyst is very sensitive to air and water, it was loaded under dry nitrogen. Synthetic feedstocks were prepared by mixing $n$-pentane, cyclohexane and a C6 cut. Before injection, 
feedstocks were first dried over 3A sieves. In the pilot unit, the feed vessel was de-aerated by successive nitrogen bubbling followed by vacuum drawing. Finally, the feed was spiked with tetrachloroethylene. The latter decomposes on the platinum releasing $\mathrm{HCl}$, which allows maintaining a constant number of acid sites on catalyst surface. Feed and hydrogen were injected at the bottom of the reactor, heated and mixed in an inert zone before contacting the catalyst. The temperature of the reactor was maintained by six independent electric heating elements and the temperature inside the reactor was measured by 3 thermocouples. Lastly, the isomerate was analyzed by on-line gas phase chromatography.

During the tests, the reactor temperature ranged from $110^{\circ} \mathrm{C}$ to $170^{\circ} \mathrm{C}$. The pressure was varied between $20 \mathrm{barg}$ and 60 barg. The Weight Hourly Space Velocity (WHSV), defined as the feed mass flow rate divided by the weight of loaded catalyst, was varied between $0.8 \mathrm{~h}^{-1}$ and $2 \mathrm{~h}^{-1}$. Finally, the inlet molar hydrogen to hydrocarbon ratio was varied from 0.05 to $0.3 \mathrm{~mol} / \mathrm{mol}$. Under these operating conditions, the hydrocarbons are mainly in liquid phase.

The analysis of the effluent showed that, during the process, skeletal isomerization of paraffins and naphthenes, ring opening, and cracking of C6 paraffins into lighter compounds take place. The data collected for $\mathrm{C} 5 / \mathrm{C} 6$ isomerization also showed that catalyst performances increase with increasing temperature and with decreasing Weight Hourly Space Velocity, while higher total pressures enhance the catalyst performances. It was also observed that naphthenes inhibit the catalyst activity due to their adsorption on acid sites. As for the molar hydrogen to hydrocarbon ratio, it has no impact on the performances. Finally, the analysis of isomerate compositions showed that 2-methyl pentane, 3-methyl pentane and 2,3-dimethyl butane always reached thermodynamic equilibrium. The same observation was made for the two C6 cycloalkanes.

\subsection{Reaction Network}

As mentioned previously, the first step of single events modeling is the identification of the reaction mechanism. For the isomerization of C5-C6 cuts, a bifunctional mechanism is assumed as proposed by Mills et al. (1953). This means that olefins are formed on the metallic sites from paraffins and naphthenes. These olefins are then protonated into acyclic or cyclic carbenium ions. The resulting ions can subsequently undergo isomerization reactions, such as hydride, methyl and ethyl shifts, and PCP (Protonated CycloPropane) branching, or $\beta$-scission reactions. All these elementary steps are depicted in Figure 2.

The computer algorithm developed at the "Laboratorium voor Petrochemische Techniek" (Baltanas and Froment, 1985; Baltanas et al., 1989; Vynckier and Froment, 1991) was used to generate the reaction network for the C5-C6 isomerization process. The feedstock components given as input were $n$-pentane, $n$-hexane, cyclopentane and cyclohexane. In the network, primary carbenium ions and the methyl ion are assumed to be too unstable to play a significant role in this process. As a consequence, their formation was not allowed in the network generation algorithm. The complete network for C5-C6 isomerization includes 56 compounds (8 paraffins, 3 naphthenes, 19 acyclic olefins, 5 cyclic olefins, 1 diolefin and 20 carbenium ions) and 167 elementary steps ( 25 dehydrogenations, 25 hydrogenations, 32 protonations, 32 deprotonations, 50 acid surface isomerizations, 1 acyclic $\beta$-scission, 1 endocyclic $\beta$-scission, 1 cyclisation). As the whole network can not be presented clearly in one single picture, it has been split over the next four figures.

Figure 11 represents the partial network involving C5 acyclic compounds.

Figure 12 represents the partial network involving C5 cyclic compounds. As ring opening of a cyclopentyl cation would lead to a primary carbenium ion, this route has not been considered.

The generated network for the C6 acyclic compounds is shown in Figure 13, while that for the C6 cyclic compounds is depicted in Figure 14.

\subsection{Late Lumping}

As mentioned previously, it is commonly accepted that the hydrogenation/dehydrogenation reactions on the metal phase reach thermodynamic equilibrium in the conditions of skeletal isomerization of C5 and C6 paraffins. As the protonation/ deprotonation steps are easily carried out under these conditions, it is assumed that these steps are also at thermodynamic equilibrium. Hence, the protonation and deprotonation rate coefficients can not be estimated independently, as only their ratio, i.e. the adsorption coefficients on the acid sites, influences the concentration of the surface carbenium ions, and therefore the rate of transformation.

As a second consequence, hydride shift steps necessarily reach equilibrium because the species involved are also connected through several protonation/deprotonation steps. Hence, a paraffin can be lumped with its corresponding olefins and their resulting carbenium ions without loss of information. The same is true for the naphthenes, their corresponding olefins and carbenium ions.

Moreover, since the analysis of isomerate compositions showed that 2-methyl pentane, 3-methyl pentane and 2,3dimethyl butane always reached thermodynamic equilibrium, those species and their corresponding olefins and carbenium ions can be grouped further into a single lump. For the same reason, all naphthenic species with 6 carbon atoms can be lumped.

Hence, in the case of isomerization, the following 8 lumps are adequate to describe the entire set of transformations:

- the propane lump which includes propane, propylene and the propyl ion; 


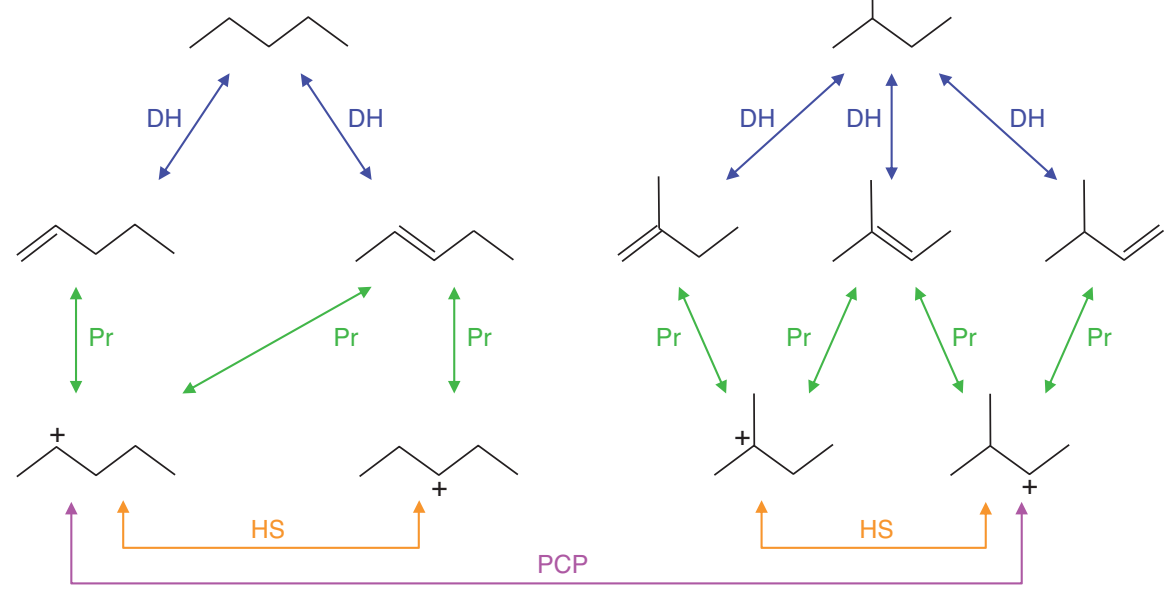

Figure 11

Reaction network involving C5 acyclic compounds.

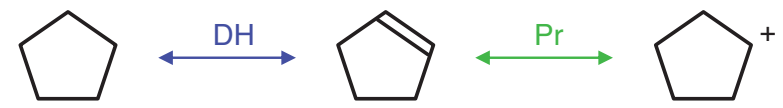

Figure 12

Reaction network involving C5 cyclic compounds.

- the $n$-pentane lump in which $n$-pentane, $n$-pentenes, and $n$-pentyl ions are grouped;

- the isopentane lump which contains 2-methyl butane, 2-methyl butenes and 2-methyl butyl ions;

- the cyclopentane lump which takes in cyclopentane, cyclopentenes and cyclopentyl ions;

- the $n$-hexane lump which includes $n$-hexane, $n$-hexenes, and $n$-hexyl ions;

- the "iC6" lump which includes 2-methyl pentane, 3-methyl pentane and 2,3-dimethyl butane and their corresponding olefins and carbenium ions;

- the 2,2-dimethyl-butane lump which contains 2,2dimethyl butane, 2,2-dimethyl butenes and 2,2-dimethyl butyl ions;

- the "N6" lump in which naphthenes with 6 carbon atoms and their corresponding olefins and carbenium ions are grouped.

The apparent reaction network can be summarized in Figure 15.

The comparison of the exhaustive reaction network generated by the algorithm and the apparent network allows identifying the kinetic parameters pertaining to the rate determining steps. In total, there are 5 different transformations between the various lumps of the apparent reaction network, and these are defined by 7 different rate coefficients listed below:

- 3 isomerization reactions governed by 5 rate coefficients (secondary-tertiary and tertiary-secondary methyl shift, and secondary-secondary, secondary-tertiary and tertiarysecondary PCP);

- 1 cracking reaction characterized by 1 rate coefficient (secondary-secondary $\beta$-scission);

- 1 ring opening reaction described by 1 rate coefficient (secondary-secondary ring opening).

\subsection{Rate Equations}

The pathways between saturated measurable species involve hydrogenation/dehydrogenation on the metal phase, protonation/deprotonation on the acid phase followed by reaction on the acid phase. The rates of formation for the various species are written by taking into account all the possible reactions that transform or produce the involved molecules.

The formation rates of paraffins only involve hydrogenation and dehydrogenation on the metal phase:

$$
R\left(P_{i}\right)=\sum_{j \in \text { Deh } P_{i}}\left(k_{h y d}(j ; i) P_{O_{j}} P_{\mathrm{H}_{2}}-k_{\text {deh }}(i ; j) P_{i}\right)
$$

with $\operatorname{Deh} P_{i}=\left\{P_{i} \leftrightarrow O_{j}+\mathrm{H}_{2}\right\}$ the set of dehydrogenation reactions transforming a paraffin $P_{i}$ into an olefin $O_{j}$.

The formation rates of the olefins are due to contribution of the metal phase via hydrogenation and dehydrogenation 


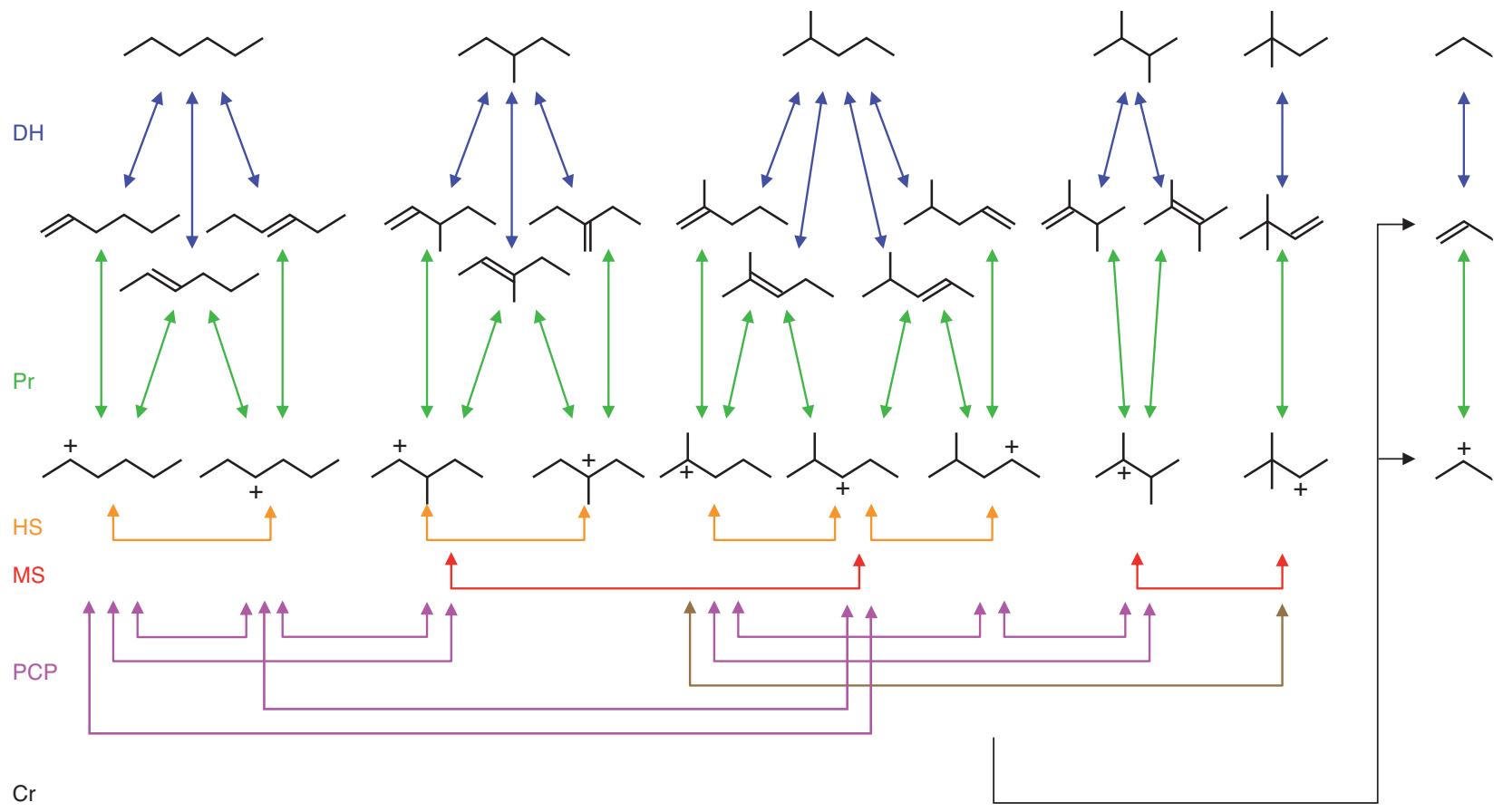

Figure 13

Reaction network involving C6 acyclic compounds.

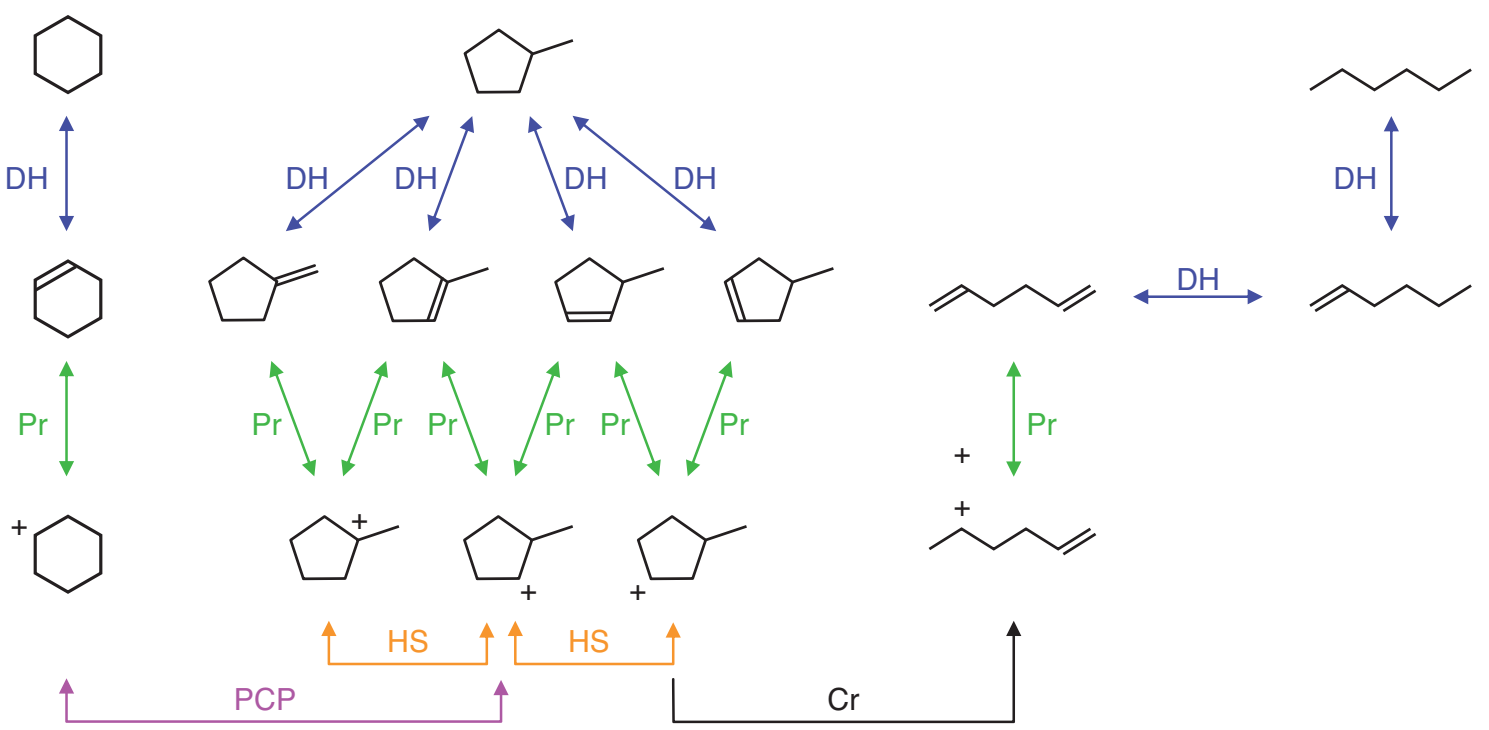

Figure 14

Reaction network involving C6 cyclic compounds. 


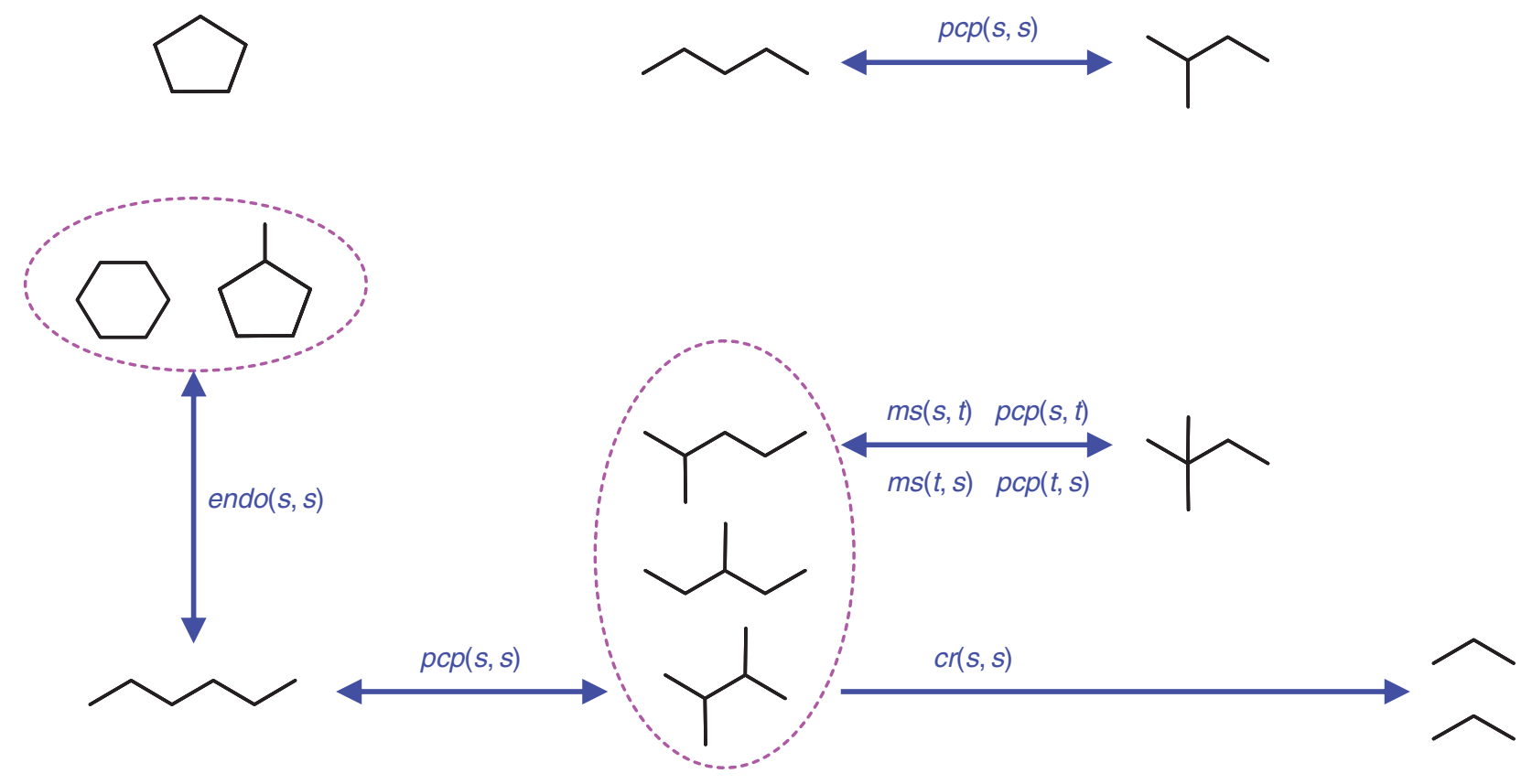

Figure 15

Apparent reaction network and corresponding rate determining steps.

and to contribution of the acid phase via protonation, deprotonation, and cracking:

$$
\begin{aligned}
R\left(O_{j}\right) & =k_{d e h}(i ; j) P_{i}-k_{h y d}(j ; i) P_{O_{j}} P_{\mathrm{H}_{2}} \\
& +\sum_{k \in D e h O_{j}}\left(k_{h y d}(k ; j) P_{D O_{k}} P_{\mathrm{H}_{2}}-k_{d e h}(j ; k) P_{O_{j}}\right) \\
& +\sum_{m \in \text { ProO }}\left(k_{d e p}\left(m ; O_{j}\right)\left[R_{m}^{+}\right]-k_{p r}(m) P_{O_{j}}\left[\mathrm{H}^{+}\right]\right) \\
& +\sum_{y \in A l k O_{j}}\left(k_{c r}(y ; m)\left[R_{y}^{+}\right]-k_{a l k}\left(m, O_{j} ; y\right)\left[R_{m}^{+}\right] P_{O_{j}}\right)
\end{aligned}
$$

with $\operatorname{Deh} O_{j}=\left\{O_{j} \leftrightarrow D O_{k}+\mathrm{H}_{2}\right\}$ the set of dehydrogenation reactions transforming an olefin $O_{j}$ into a diolefin $D O_{k}$. Pro $O_{j}=\left\{O_{j}+\mathrm{H}^{+} \leftrightarrow R_{m}^{+}\right\}$the set of protonation reactions transforming an olefin $O_{j}$ into a carbenium ion $R_{m}^{+}$. Alk $O_{j}=\left\{O_{j}+R_{n}^{+} \leftrightarrow R_{y}^{+}\right\}$the set of alkylation reactions involving an olefin $O_{j}$ and a carbenium ion $R_{n}^{+}$producing a carbenium ion $R_{y}^{+}$.

The formation rates of the carbenium ions are only due to the acid phase, via protonation and deprotonation and via the surface reactions (isomerization, cracking, alkylation):

$$
\begin{aligned}
R\left(R_{m}^{+}\right)= & \sum_{k \in \text { Dep } m}\left(k_{p r}(m) P_{O_{k}}\left[\mathrm{H}^{+}\right]-k_{d e p}\left(m ; O_{j}\right)\left[R_{m}^{+}\right]\right) \\
& +\sum_{v \in M S m}\left(k_{M S}(v ; m)\left[R_{v}^{+}\right]-k_{M S}(m ; v)\left[R_{m}^{+}\right]\right) \\
& +\sum_{w \in P C P m}\left(k_{P C P}(w ; m)\left[R_{v}^{+}\right]-k_{P C P}(m ; w)\left[R_{m}^{+}\right]\right) \\
& +\sum_{y \in C r m}\left(k_{a l k}(y ; m)\left[R_{y}^{+}\right] P_{O_{l}}-k_{c r}(m ; y)\left[R_{m}^{+}\right]\right) \\
& +\sum_{z \in A l k m}\left(k_{c r}(m ; z)\left[R_{z}^{+}\right]-k_{a l k}(z ; m)\left[R_{m}^{+}\right] P_{O_{l}}\right)
\end{aligned}
$$

with Dep $m=\left\{R_{m}^{+} \leftrightarrow O_{k}+\mathrm{H}^{+}\right\}$the set of deprotonation reactions transforming a carbenium ion $R_{m}^{+}$into an olefin $O_{j}$.

$M S m=\left\{R_{m}^{+} \stackrel{M S}{\leftrightarrow} R_{v}^{+}\right\}$the set of methyl shift reactions transforming a carbenium ion $R_{m}^{+}$into a carbenium ion $R_{v}^{+}$. PCP $m=\left\{R_{m}^{+} \stackrel{P C P}{\leftrightarrow} R_{v}^{+}\right\}$the set of PCP branching reactions transforming a carbenium ion $R_{m}^{+}$into a carbenium ion $R_{v}^{+}$.

Cr $m=\left\{R_{m}^{+} \leftrightarrow R_{v}^{+}+O_{n}\right\}$ the set of $\beta$-scissions transforming a carbenium ion $R_{m}^{+}$into an olefin $O_{n}$ and a carbenium ion $R_{v}^{+}$.

Alk $m=\left\{R_{m}^{+}+O_{n} \leftrightarrow R_{v}^{+}\right\}$the set of alkylation reactions involving a carbenium ion $R_{m}^{+}$and an olefin $O_{n}$ producing a carbenium ion $R_{v}^{+}$. 


$$
\begin{aligned}
R\left(P_{i}\right)= & \sum_{m \in C y c A b s} \sum_{i} \sum_{j \in C y c m}\left(k_{\text {CracEnd }}(j ; m)\left[N R_{j}^{+}\right]-k_{C y c}(m ; j)\left[O R_{m}^{+}\right]\right) \\
& +\sum_{m \in A b s P_{i}} \sum_{v \in M S}\left(k_{M S}(v ; m)\left[R_{v}^{+}\right]-k_{M S}(m ; v)\left[R_{m}^{+}\right]\right) \\
& +\sum_{m \in A b s P_{i}} \sum_{v \in P C P}\left(k_{P C P}(v ; m)\left[R_{v}^{+}\right]-k_{P C P}(m ; v)\left[R_{m}^{+}\right]\right) \\
& +\sum_{m \in A b s P_{i}} \sum_{y \in C r m}\left(k_{a l k}(y ; m)\left[R_{y}^{+}\right] P_{O_{l}}-k_{c r}(m ; y)\left[R_{m}^{+}\right]\right) \\
& +\sum_{m \in A b s P_{i}} \sum_{z \in A l k m}\left(k_{a l k}(z ; m)\left[R_{m}^{+}\right] P_{O_{l}}-k_{c r}(m ; y)\left[R_{z}^{+}\right]\right) \\
& +\sum_{j \in \text { Deh } P_{i}}\left(\sum_{y \in A l k O_{j}}\left(k_{c r}(y ; m)\left[R_{y}^{+}\right]-k_{a l k}\left(m, O_{j} ; y\right)\left[R_{m}^{+}\right] P_{O_{j}}\right)\right)
\end{aligned}
$$

The formation rates of the diolefins are due to contribution of the metal phase via hydrogenation and dehydrogenation and to contribution of the acid phase via protonation and deprotonation.

$$
\begin{aligned}
R\left(D O_{j}\right) & =\sum_{k \in H y d D O_{j}}\left(k_{\text {deh }}(k ; j) P_{O_{k}}-k_{h y d}(j ; k) P_{D O_{j}} P_{\mathrm{H}_{2}}\right) \\
& +\sum_{m \in \text { Pro DO }_{j}}\left(k_{\text {dep }}\left(m ; D O_{j}\right)\left[O R_{m}^{+}\right]-k_{p r}(m) P_{D O_{j}}\left[\mathrm{H}^{+}\right]\right)
\end{aligned}
$$

with Hyd $D O_{j}=\left\{D O_{j}+\mathrm{H}_{2} \leftrightarrow O_{k}\right\}$ the set of hydrogenation reactions transforming a diolefin $D O_{j}$ into an olefin $O_{k}$. Pro $D O_{j}=\left\{D O_{j}+\mathrm{H}^{+} \leftrightarrow O R_{m}^{+}\right\}$the set of protonation reactions transforming a diolefin $D O_{j}$ into an olefinic carbenium ion $O R_{m}^{+}$.

The formation rates of the olefinic carbenium ions are only due to the acid phase, via protonation and deprotonation, and via the surface reactions (cracking, cyclization):

$$
\begin{aligned}
R\left(O R_{m}^{+}\right)= & \sum_{k \in \text { DepOR }}\left(k_{p r}(m) P_{D O_{j}}\left[\mathrm{H}^{+}\right]-k_{\text {dep }}\left(m ; D O_{j}\right)\left[O R_{m}^{+}\right]\right) \\
& +\sum_{j \in C y c m}\left(k_{\text {CracEnd }}(j ; m)\left[N R_{j}^{+}\right]-k_{C y c}(m ; j)\left[O R_{m}^{+}\right]\right)
\end{aligned}
$$

with Dep $O R_{m}=\left\{O R_{m}^{+} \leftrightarrow D O_{j}+\mathrm{H}^{+}\right\}$the set of deprotonation reactions transforming an olefinic carbenium ion $O R_{m}^{+}$into a diolefin $D O_{j}$.

Cyc $m=\left\{O R_{m}^{+} \leftrightarrow N R_{j}^{+}\right\}$the set of cyclization reactions transforming an olefinic carbenium ion $O R_{m}^{+}$into a cyclic carbenium ion $N R_{j}^{+}$.

As the olefins, the diolefins, and all carbenium ion intermediates are not measurable and in very small quantities compared to the saturated species, the quasi steady state assumption is made for these species, leading to the following equation: see Equation (40).

with $A b s P_{i}+\left\{P_{i}+\mathrm{H}^{+} \leftrightarrow R_{m}^{+}\right\}$the set of combined dehydrogenation/protonation reactions transforming a paraffin $P_{i}$ into a carbenium ion $R_{m}^{+}$.

CyclAbs $P_{i}=\left\{P_{i}+\mathrm{H}^{+} \leftrightarrow N R_{m}^{+}+2 \mathrm{H}_{2}\right\}$ the set of combined dehydrogenation/protonation reactions transforming a paraffin $P_{i}$ into and cyclic carbenium ion $N R_{m}^{+}$. A similar equation is obtained for the naphthenes.

The equilibrium assumptions yield the following equations:

$$
\begin{gathered}
P_{O_{j}}=K_{\text {deh/hyd }}\left(P_{i}, O_{j}\right) \cdot \frac{P_{P_{i}}}{P_{\mathrm{H}_{2}}} \\
P_{N O_{j}}=K_{\text {deh/hyd }}\left(N_{i}, N O_{j}\right) \cdot \frac{P_{N_{i}}}{P_{\mathrm{H}_{2}}} \\
P_{D O_{k}}=K_{\text {deh//hyd }}\left(O_{j}, D O_{k}\right) \cdot \frac{P_{O_{j}}}{P_{\mathrm{H}_{2}}} \\
{\left[R_{m}^{+}\right]=K_{p r / d e p}\left(O_{j}, m\right) \cdot P_{O_{j}} \cdot\left[\mathrm{H}^{+}\right]} \\
{\left[O R_{n}^{+}\right]=K_{p r / d e p}\left(D O_{k}, n\right) \cdot P_{D O_{k}} \cdot\left[\mathrm{H}^{+}\right]} \\
{\left[N R_{l}^{+}\right]=K_{p r / d e p}\left(N O_{j}, l\right) \cdot P_{N O_{j}} \cdot\left[\mathrm{H}^{+}\right]}
\end{gathered}
$$

The free acid site balance is given by:

$$
\left[\mathrm{H}^{+}\right]+\sum_{m} R_{m}^{+}+\sum_{n} O R_{n}^{+}+\sum_{l} N R_{l}^{+}=1
$$


The equations above constitute the generic differentioalgebraic system of equations that needs to be solved.

As mentioned before, the reactions on the metal phase are assumed to reach thermodynamic equilibrium. Hence, only the thermodynamic equilibrium constants of these steps are required. In order to be consistent, these constants have been calculated by means of the Benson group contribution method (Benson et al., 1969; Benson, 1976).

The thermodynamic equilibrium in the protonation/ deprotonation steps leads to 3 adsorption constants $\tilde{K}_{\text {ads }}$, which, unlike the hydrogenation/dehydrogenation constants, must be estimated since they are not known and can not be directly calculated.

The 7 kinetic parameters of the rate determining steps must also be estimated from the experimental data. However, due to the thermodynamic constraints, the number of independent rate parameters is reduced to 5. Indeed, the intrinsic rate coefficient for the secondary-tertiary isomerization reactions (methyl-shift and $\mathrm{PCP}) k_{i s o}(s, t)$ can be calculated from the intrinsic rate coefficient for the tertiarysecondary isomerization reactions $k_{i s o}(t, s)$. This reduces the number of independent rate parameters for isomerization to three: $k_{p c p}(s, s), k_{p c p}(s, t), k_{m s}(s, t)$.

In total, 8 coefficients are required, resulting in 16 parameters to be estimated, as each rate coefficient is decomposed into a pre-exponential factor and an activation energy or adsorption enthalpy.

\subsection{Reactor Model}

The isomerization experiments were performed in an isothermal and isobaric plug flow reactor. It was assumed that the vapour-liquid equilibrium is established throughout the entire reactor and that there are no external or internal diffusion limitations.

Hence, the continuity equations for the independent components or lumps reduce to a set of ordinary differential equations written as follows:

$$
\frac{d F_{j}(z)}{d z}=\rho_{\text {catbed }} \Omega_{R} R_{j} \quad \text { for } j=1, n_{j}
$$

where: $F_{j}(z)$ is the molar flow rate of component or lump $j$ at position $z\left(\mathrm{~mol}_{\mathrm{j}} / \mathrm{h}\right)$,

$z \quad$ the axial reactor coordinate $\left(\mathrm{m}_{R}\right)$,

$\rho_{\text {catbed }}$ the bulk density of the catalyst bed $\left(\mathrm{kg}_{\text {cal }} / \mathrm{m}_{R}{ }^{3}\right)$,

$\Omega_{R} \quad$ the cross section of the reactor $\left(\mathrm{m}_{R}^{2}\right)$,

$R_{j} \quad$ the net specific rate of production of component or lump $j\left(\mathrm{~mol}_{j} / \mathrm{kg}_{\text {cat }} / \mathrm{h}\right)$,

$n_{j} \quad$ the number of hydrocarbon components or lumps $j(-)$, or, since:

$$
d w_{\text {cat }}=\rho_{\text {catbed }} \Omega_{R} \cdot d z
$$

where $w_{c a t}$ is the catalyst mass, the continuity equations can be written as:

$$
\frac{d F_{j}(w)}{d w_{c a t}}=R_{j} \quad \text { for } j=1, n_{j}
$$

The net specific rate of production is calculated from the rate equations of the single-events kinetic model, described in the previous section.

The set of ordinary differential equations is solved numerically by means of the Livermore Solver for Ordinary Differential Equations, (LSODE) (Hindmarsch, 1980, 1983). This routine allows the integration of stiff and non-stiff initial boundary problems of ordinary differential equations. The set of differential equations is solved with the initial values being the inlet flow rates of the $n_{j}$ components or lumps:

$$
F_{j}(0)=F_{j}^{0} \quad \text { for } j=1, n_{j}
$$

where $F_{j}^{0}$ is the reactor inlet flow rate of component or lump $j$.

\subsection{Identification of the Kinetic Parameters and Precision of the Adjusted Model}

The objective of the paraffin isomerization process is to obtain a good octane number of the isomerate, i.e. the $\mathrm{C} 4+$ cut, while minimizing the losses by cracking. As a consequence, the model has to accurately predict the yields of branched isomers and also the yield of propane. The parameters of the kinetic model were identified by means of a Levenberg-Marquardt algorithm (Levenberg, 1944; Marquardt,

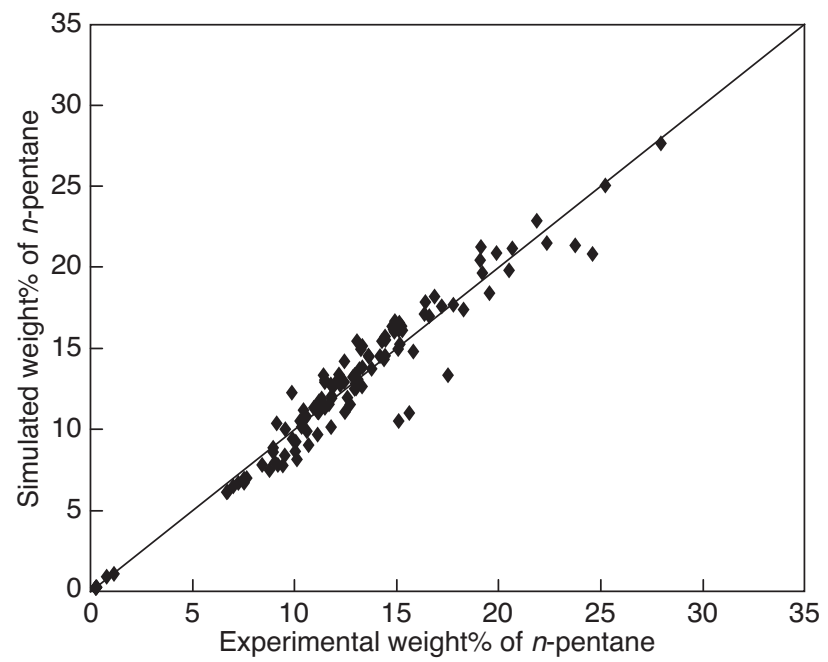

Figure 16

Parity diagram for the weight percentage of $n$-pentane at outlet of the isomerization reactor. 


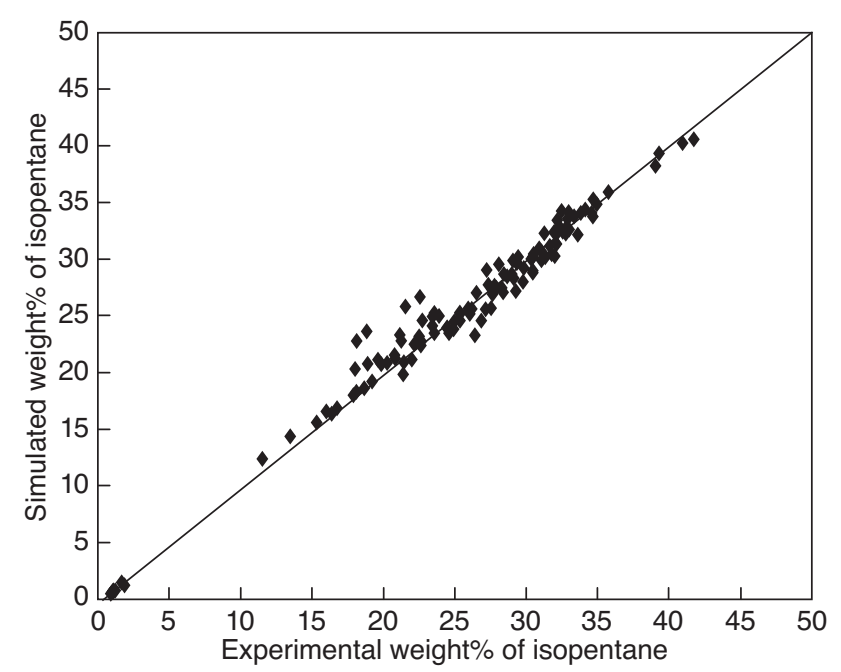

Figure 17

Parity diagram for the weight percentage of isopentane at outlet of the isomerization reactor.

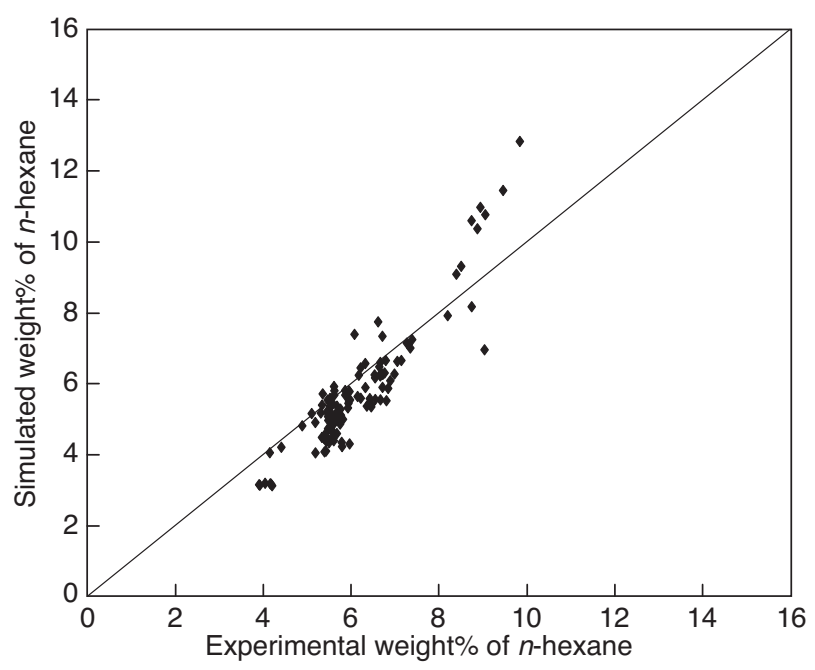

Figure 18

Parity diagram for the weight percentage of $n$-hexane at outlet of the isomerization reactor.

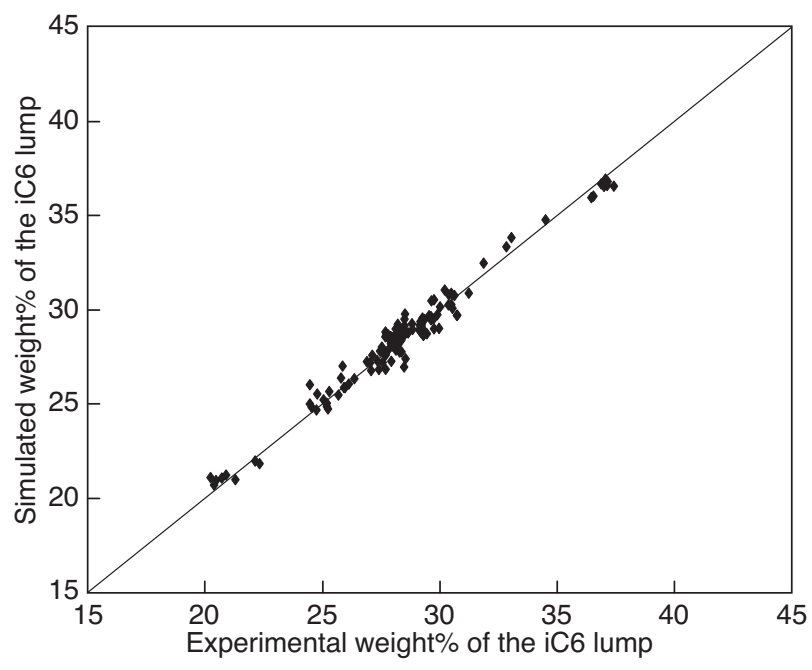

Figure 19

Parity diagram for the weight percentage of the iC6 lump (2-methyl pentane, 3-methyl pentane and 2,3-dimethyl butane) at outlet of the isomerization reactor.

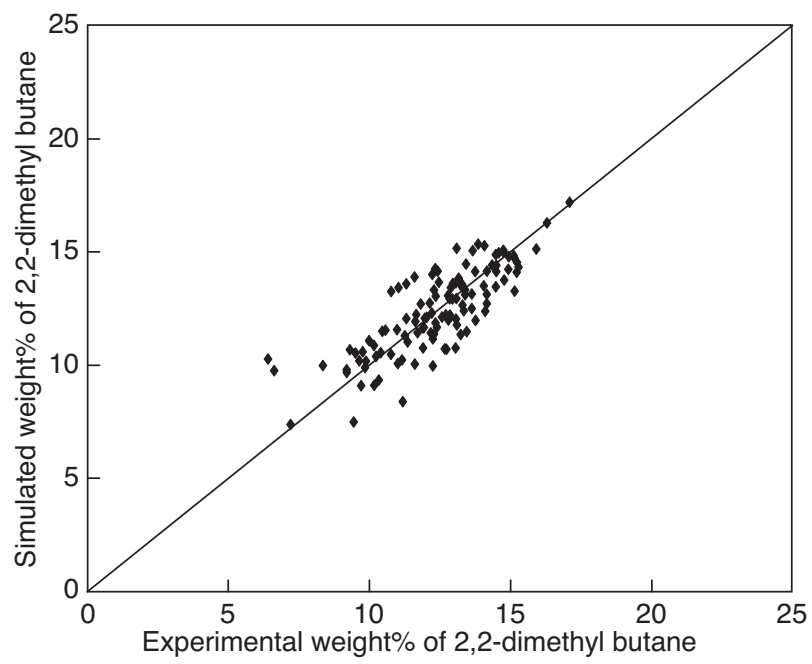

Figure 20

Parity diagram of the weight percentage for 2,2-dimethyl butane at outlet of the isomerization reactor.
1963). The parameter values were obtained by minimizing the weighted sum of the squares of the differences between the experimental and simulated results. At the optimum, a statistical analysis was performed: all calculated $t$-values were higher than 7.3, indicating that the parameter estimates were statistically significant. No noteworthy correlation between the various parameters was observed.

Figure 16 and Figure 17 respectively show the weight percentage of $n$-pentane and of isopentane predicted by the model against the weight percentage obtained experimentally. This figure shows that the model predicts quite well the conversion of $n$-pentane towards isopentane. The precision of the model for prediction of these components in the experimental range is about $\pm 5 \mathrm{wt} \%$.

Similar precisions $( \pm 5 \mathrm{wt} \%)$ are also obtained for the n-hexane (Fig. 18), the "iC6" lump (Fig. 19), 2,2 dimethyl butane (Fig. 20), and the "N6" lump (Fig. 21) over the entire experimental range, even at high conversion. As a 


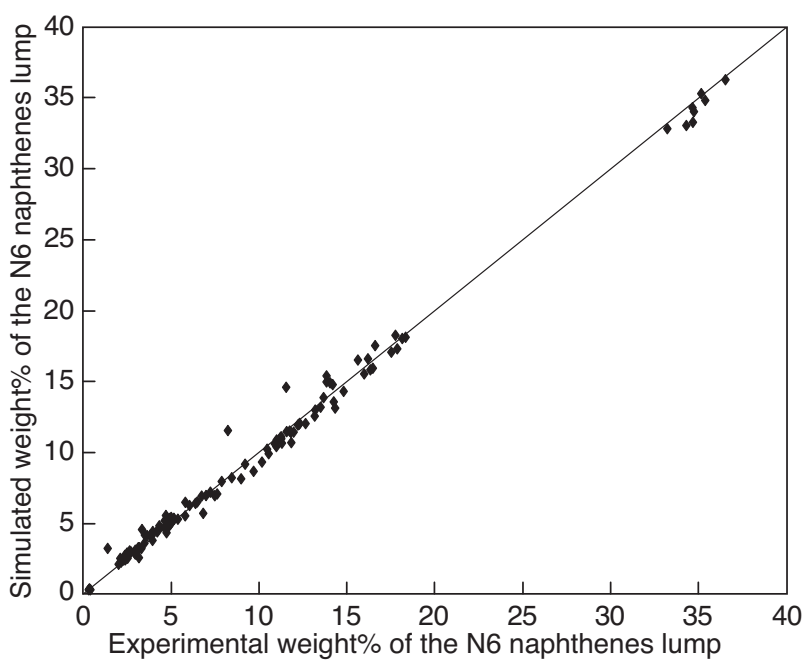

Figure 21

Parity diagram of the weight percentage of N6 naphthenes at outlet of the isomerization reactor.

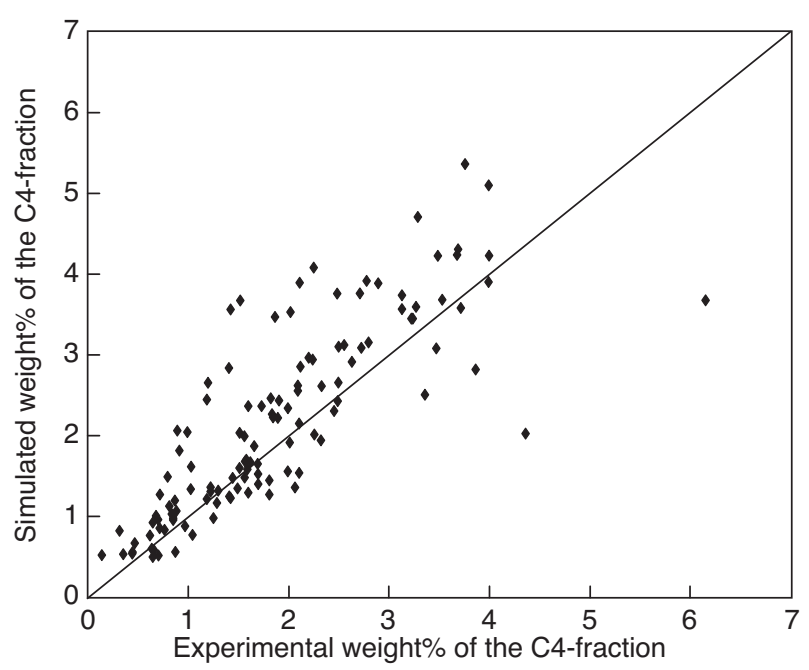

Figure 22

Parity diagram of the weight percentage of $\mathrm{C} 4$ minus components at outlet of the isomerization reactor.

consequence, a good precision is obtained for the prediction of the octane number of the isomerate.

The parity diagram for the production of light products, i.e. the $\mathrm{C}_{4}$ minus fraction, through cracking is plotted in Figure 22. As for other compounds, the amount of cracked products produced is quite well predicted given the analytical precision and the low quantities of cracked products present in the effluent.

As shown in the application, the single-event methodology allows to build a kinetic model that is representative of the catalytic performances in industrial conditions. In the case of isomerization of $\mathrm{C} 5-\mathrm{C} 6$ cuts, the method allows to obtain a good agreement with the experimental data. Moreover, as the fundamental single-event rate coefficients are independent of the number of atoms in the molecules, extension to larger carbon numbers, as for isomerization of $\mathrm{C} 7$ cuts, is straightforward and only adds a few extra kinetic parameters corresponding to the additional reaction types.

\section{CONCLUSION}

In this work, the single-event methodology was used to model the isomerization of C5-C6 cuts. This methodology is based on the fundamental understanding of the chemistry and consists in constructing an exhaustive computer-generated reaction network. Applying the principles of the single-event theory and introducing thermodynamic constraints between some of the parameters allows to simulate huge networks using only a limited number of independent fundamental kinetic parameters.

In the case of C5-C6 isomerization, the entire network includes 56 compounds and 167 elementary steps. Applying the principles of the single-event theory and regrouping the species at equilibrium into lumps via late-lumping methods, the number of parameters to be identified was reduced to 8 coefficients. After parameter identification, the developed model is consistent with the experimentally obtained results and representative of industrial conditions.

The single-event method represents an extremely elegant approach for the modeling of acid catalysed processes, such as isomerization, catalytic reforming catalytic cracking, and hydrocracking. Indeed, the single-event methodology offers two advantages: first of all, it allows the development of a detailed model described by a limited number of independent kinetic parameters; secondly, since these rate coefficients are independent of the number of carbon atoms in the molecules, it is possible to identify them through studies on model molecules and therefore predict the behaviour of complex feedstocks from experimental data that can be acquired more easily.

\section{ACKNOWLEDGMENTS}

The authors would like to acknowledge Arnaud Cordier, Carole Michon, and Patrice Canario for their help with the experimental work.

\section{REFERENCES}

Baltanas M.A., Froment G.F. (1985) Computer generation of reaction networks and calculation of product distributions in the hydroisomerization and hydrocracking of paraffins on Pt-containing bifunctional catalysts, Comput. Chem. Eng. 9, 1, 71-81. 
Baltanas M.A., Van Raemdonck K.K., Froment G.F., Mohedas S.R. (1989) Fundamental kinetic modeling of hydroisomerization and hydrocracking on noble-metal-loaded faujasites. 1. Rate parameters for hydroisomerization, Ind. Eng. Chem. Res. 28, 899-910.

Beirnaert H.C., Alleman J.R., Marin G.B. (2001) A Fundamental Kinetic Model for the Catalytic Cracking of Alkanes on a USY Zeolite in the Presence of Coke Formation, Ind. Eng. Chem. Res. 40, 5, 1337-1347

Benson S.W., Cruickshank F.R., Golden D.M., Haugen G.R., O'Neal H.E., Rodgers A.S., Shaw R., Walsch R. (1969) Additivity rules for estimation of thermodynamical properties, Chem. Rev. 69 , 279-324.

Benson S.W. (1976) Thermochemical Kinetics, 2nd ed., John Wiley \& Sons, New York.

Chavarría-Hernández J.C., Ramírez J., Gonzalez H., Baltanas M.A. (2004) Modelling of $n$ Hexadecane Hydroisomerization and Hydrocracking Reactions on a Mo/H Beta-Alumina Bi-Functional Catalyst Using the Single Event Concept, Catal. Today 98, 1-2, 235-242.

Chavarría-Hernández J.C., Ramírez J., Baltanas M.A. (2008) Single-Event-Lumped-Parameter Hybrid (SELPH) model for nonideal hydrocracking of $n$-octane, Catal. Today 130, 2-4, 455-461.

Chavarría-Hernández J.C., Ramírez J. (2009) Modeling Ideal and Nonideal Hydrocracking of Paraffins Using the Single-Event Lumped Parameter Hybrid (SELPH) Model, Ind. Eng. Chem. Res. 48, 3, 1203-1207.

Choudhury I.R., Thybaut J.W., Balasubramanian P., Denayer J.F.M., Martens J.A., Marin G.B. (2010) Synergy between shape selective and non-shape selective bifunctional zeolites modelled via the Single-Event MicroKinetic (SEMK) methodology, Chem. Eng. Sci. 65, 174-178.

Clymans P.J., Froment G.F. (1984) Computer generation of reaction paths and rate equations in the thermal cracking of normal and branched paraffins, Comput. Chem. Eng. 8, 2, 137-142.

Dewachtere N.V., Santaella F., Froment G.F. (1999) Application of a single-event kinetic model in the simulation of an industrial riser reactor for the catalytic cracking of vacuum gas oil, Chem. Eng. Sci. 54, 15-16, 3653-3660.

Feng W., Vynckier E., Froment G.F. (1993) Single-event kinetics of catalytic cracking, Ind. Eng. Chem. Res. 32, 12, 2997-3005.

Froment G.F. (2005) Single Event Kinetic Modeling of Complex Catalytic Processes, Catal.Rev. 47, 83-124.

Guillaume D., Surla K., Galtier P. (2003) From Single Events theory to molecular kinetics: application to industrial process modeling, Chem. Eng. Sci. 58, 21, 4861-4869.

Hillewaert L.P., Dierickx J.L., Froment G.F. (1988) Computer generation of reaction schemes and rate equations for thermal cracking, AIChE J. 34, 1, 17-24.

Hindmarsch A.C. (1980) LSODE and LSODI, Two New Initial Value Ordinary Differential Equation Solvers, ACM Signum Newsl. 15, 4, 19-21.

Hindmarsch A.C. (1983) ODEPACK, a systematized collection of ODE solvers, in Scientific Computing, Stepleman R.S. et al. (eds), IMACS, North-Holland, Amsterdam, pp. 55-64.

Kazansky V.B., Frash M.V., van Santen R.A. (1996) Quantumchemical study of the isobutane cracking on zeolites, Appl. Catal. A: Gen. 146, 1, 225-247.

Kazansky V.B. (1999) Adsorbed carbocations as transition states in heterogeneous acid catalyzed transformations of hydrocarbons, Catal. Today 51, 3-4, 419-434.

Kumar H., Froment G.F. (2007a) A generalized mechanistic kinetic model for the hydroisomerization and hydrocracking of long-chain paraffins, Ind. Eng. Chem. Res. 46, 12, 4075-4090.
Kumar H., Froment G.F. (2007b) Mechanistic Kinetic Modeling of the Hydrocracking of Complex Feedstocks, such as Vacuum Gas Oils, Ind. Eng. Chem. Res. 46, 18, 5881-5897.

Laxmi Narasimhan C.S., Thybaut J.W., Marin G.B., Martens J.A., Denayer J.F., Baron G.V. (2003a) Pore mouth physisorption of alkanes on ZSM-22: estimation of physisorption enthalpies and entropies by additivity method, J. Catal. 218, 1, 135-147.

Laxmi Narasimhan C.S., Thybaut J.W., Marin G.B., Jacobs P.A., Martens J.A., Denayer J.F., Baron G.V. (2003b) Kinetic modeling of pore mouth catalysis in the hydroconversion of $n$-octane on $\mathrm{Pt}-\mathrm{H}$ ZSM-22, J. Catal. 220, 2, 399-413.

Laxmi Narasimhan C.S., Thybaut J.W., Marin G.B., Denayer J.F., Baron G.V., Martens J.A., Jacobs P.A. (2004) Relumped singleevent microkinetic model for alkane hydrocracking on shape-selective catalysts: catalysis on ZSM-22 pore mouths, bridge acid sites and micropores, Chem. Eng. Sci. 59, 22-23, 4765-4772.

Laxmi Narasimhan C.S., Thybaut J.W., Martens J.A., Jacobs P.A., Denayer J.F., Marin G.B. (2006) A unified single-event microkinetic model for alkane hydroconversion in different aggregation states on Pt/H-USY-zeolites, J. Phys. Chem. B 110, 13, 6750-6758.

Laxmi Narasimhan C.S., Thybaut J.W., Denayer J.F., Baron G.V., Jacobs P.A., Martens J.A., Marin G.B. (2007) Aggregation state effects in shape-selective hydroconversion, Ind. Eng. Chem. Res. 46, 25, 8710-8721.

Lenoir D., Siehl H.U. (1990) Carbokationen, Carbokation-Radikale, in Methoden der Organische Chemie, Vierte Auflage, Hamack M. (ed.), Georg Thieme Verlag, Stuttgart.

Levenberg K. (1944) A Method for the Solution of Certain Problems in Least Squares, Quart. Appl. Math. 2, 2, 164-168.

Lozano-Blanco G., Thybaut J.W., Surla K., Galtier P., Marin G.B. (2006) Fischer-Tropsch Synthesis: Development of a Microkinetic Model for Metal Catalysis, Oil Gas Sci. Technol. 61, 4, 489-496.

Lozano-Blanco G., Thybaut J.W., Surla K., Galtier P., Marin G.B. (2008) Single-Event Microkinetic Model for Fischer-Tropsch Synthesis on Iron-Based Catalysts, Ind. Eng. Chem. Res. 47, 16, 5879-5891.

Marcilly C. (2003) Catalyse acido-basique. Vol. 1, Vol. 2, Editions Technip, Paris.

Marquardt D. (1963) An Algorithm for Least-Squares Estimation of Nonlinear Parameters, J. Soc. Ind. Appl. Math. 11, 2, 431-441.

Martens G.G., Froment G.F. (1999) Kinetic modeling of paraffins hydrocracking based upon elementary steps and the single event concept, in Reaction kinetics and the development of catalytic processes, Froment G.F., Waugh K.C. (eds), Elsevier Science BV, Stud. Surf. Sci. Catal. 122, 333-340.

Martens G.G., Marin G.B., Martens J.A., Jacobs P.A., Baron G.V. (2000) A fundamental kinetic model for hydrocracking of C8 to C12 alkanes on Pt/US-Y zeolites, J. Catal. 195, 2, 253-267.

Martens G.G., Marin G.B. (2001) Kinetics for hydrocracking based on structural classes: Model development and application, AIChE J. 47, 7, 1607-1622.

Martens G.G., Thybaut J.W., Marin G.B. (2001) Single event rate parameters for hydrocracking of cycloalkanes on Pt/US-Y zeolites, Ind. Eng. Chem. Res. 40, 1832-1844.

Martinis J.M. (2004) Single Event Kinetic Modeling of Solid Acid Alkylation of Isobutane With Butenes Over Proton-Exchanged YZeolites, PhD Thesis, Texas A\&M University, Texas (USA).

Martinis J.M., Froment G.F. (2006) Alkylation on Solid Acids. Part 2. Single-Event Kinetic Modeling, Ind. Eng. Chem. Res. 45, 3, 954-967.

Mills G.A., Heinemann H., Milliken T.H., Oblad A.G. (1953) Houdriforming reactions: Catalytic Mechanism, Ind. Eng. Chem. 45, 1, 134-137. 
Mitsios M., Guillaume D., Galtier P., Schweich D. (2009) SingleEvent Microkinetic Model for Long-Chain Paraffin Hydrocracking and Hydroisomerization on an Amorphous $\mathrm{Pt} / \mathrm{SiO}_{2}-\mathrm{Al}_{2} \mathrm{O}_{3}$ Catalyst, Ind. Eng. Chem. Res. 48, 3284-3292.

Moustafa T., Froment G.F. (2001) Kinetic Modeling of Coke Formation and Deactivation in the Catalytic Cracking of Vacuum Gas Oil, Ind. Eng. Chem. Res. 42, 1, 14-25.

Muller C., Scacchi G., Côme G.M. (1991) A topological method for determining the external symmetry number of molecules, Comput. Chem. 15, 1, 17-27.

Natal-Santiago M.A., Alcala R., Dumesic J.A. (1999) DFT Study of the Isomerization of Hexyl Species Involved in the Acid-Catalyzed Conversion of 2-Methyl-Pentene-2, J. Catal. 181, 1, 124-144.

Park T.Y., Froment G.F. (2001) Kinetic modeling of the methanol to olefins process: 1. Model formulation, Ind. Eng. Chem. Res. 40, 4172-4186.

Quintana-Solórzano R., Thybaut J.W., Marin G.B., Lødeng R., Holmen A. (2005) Single-Event MicroKinetics for coke formation in catalytic cracking, Catal. Today 107, 8, 619-629.

Quintana-Solórzano R., Thybaut J.W., Marin G.B. (2007a) A single-event microkinetic analysis of the catalytic cracking of (cyclo)alkanes on an equilibrium catalyst in the absence of coke formation, Chem. Eng. Sci. 62, 18-20, 5033-5038.

Quintana-Solórzano R., Thybaut J.W., Galtier P., Marin G.B. (2007b) Single-Event MicroKinetics for coke formation during the catalytic cracking of (cyclo)alkane/1-octene mixtures, Catal. Today 127, $1,17-30$

Quintana-Solórzano R., Thybaut J.W., Galtier P., Marin G.B. (2010) Simulation of an industrial riser for catalytic cracking in the presence of coking using Single-Event MicroKinetics, Catal. Today 150, 319-331.

Ratkiewicz A., Truong T.N. (2003) Application of Chemical Graph Theory for Automated Mechanism Generation, J. Chem. Inf. Comp. Sci. 43, 1, 36-44.

Rigby A.M., Kramer G.J., van Santen R.A. (1997) Mechanisms of Hydrocarbon Conversion in Zeolites: A Quantum Mechanical Study, J. Catal. 170, 10, 1-10.

Schweitzer J.M., Galtier P., Schweich D. (1999) A single events kinetics model for hydrocracking of paraffins in a three phase reactor, Chem. Eng. Sci. 54, 2441-2452.
Surla K., Vleeming H., Guillaume D., Galtier P. (2004) A single events kinetic model: $n$-butane isomerization, Chem. Eng. Sci. 59, 22-23, 4773-4779.

Svoboda G.D., Vynckier E., Debrabandere B., Froment G.F. (1995) Single-Event Rate Parameters for Paraffin Hydrocracking on a Pt/US-Y Zeolite, Ind. Eng. Chem. Res. 34, 11, 3793-3800.

Thybaut J.W., Marin G.B., Baron G.V., Jacobs P.A., Martens J.A. (2001) Alkene protonation enthalpy determination from fundamental kinetic modeling of alkane hydroconversion on Pt/H-(US)Y-Zeolite, J. Catal. 202, 324-339.

Thybaut J.W., Marin G.B. (2003) Kinetic Modeling of the Conversion of Complex Hydrocarbon Feedstocks by Acid Catalysis, Chem. Eng. Technol. 26, 4, 509-514.

Thybaut J.W., Laxmi Narasimhan C.S., Marin G.B., Denayer J.F.M., Baron G.V., Jacobs P.A., Martens J.A. (2004) Alkylcarbenium ion concentrations in zeolite pores during octane hydrocracking on Pt/H-USY zeolite, Catal. Lett. 94, 1-2, 81-88.

Thybaut J.W., Choudhury I.R., Denayer J.F., Baron G.V., Jacobs P.A., Martens J.A., Marin G.B. (2009) Design of optimum zeolite pore system for central hydrocracking of long-chain $n$-alkanes based on a Single-Event MicroKinetic model, Topics Catal. 52, 9, 1251-1260.

Vynckier E., Froment G.F. (1991) Modeling of the kinetics of complex processes upon elementary steps, in Kinetic and thermodynamic lumping of multicomponent mixtures, Astarita G., Sandler S.I. (eds), Elsevier Science Publishers BV, Amsterdam, pp. 131-161.

Walters W.P., Yalkowsky S.H. (1996) ESCHER - A Computer Program for the Determination of External Rotational Symmetry Numbers from Molecular Topology, J. Chem. Inf. Comp. Sci. 36, 5 , 1015-1017.

Willems P.A., Froment G.F. (1988a) Kinetic Modeling of the Thermal Cracking of Hydrocarbons. 1. Calculation of Frequency Factors, Ind.Eng. Chem. Res. 27, 11, 1959-1966.

Willems P.A., Froment G.F. (1988b) Kinetic Modeling of the Thermal Cracking of Hydrocarbons. 2. Calculation of Activation Energies, Ind.Eng. Chem. Res. 27, 11, 1966-1971.

Final manuscript received in May 2011 Published online in July 2011 